Elsevier

BRR 90054

\title{
Cholinergic Mechanisms in Depression
}

\author{
STEVEN C. DILSAVER \\ Clinical Studies Unit for Affective Disorders, Department of Psychiatry, Mental Health Research Institute, and Neuroscience \\ Laboratory, University of Michigan, Ann Arbor, MI 48104-1687 (U.S.A.)
}

(Accepted 1 April 1986)

Key words: Acetylcholine - Affective disorder - Cholinergic mechanism - Depression - Mania - Muscarinic receptor Physostigmine - Neuroendocrine - Polysomnographic study - Substance abuse - Drive-rcduction Suicide - Sleep deprivation

\section{CONTENTS}

1. Introduction

2. Strong evidence for the cholinergic hypothesis of depression

3. The phenomenological evidence

4. Neuroendocrine data

5. Polysomnographic data

6. Supersensitivity of affective disorder patients to cholinergic challenge .....

7. Moderate evidence for the cholinergic hypothesis of depression

8. The response of affective states to anticholinergic agents

9. Cholinergic-induced reduction of hedonic behavior

10. Drug withdrawal data

11. Drug abuse data

12. Tentative evidence for the cholinergic hypothesis: Brain muscarinic receptor alterations in suicide victims

13. Tentative evidence for the cholinergic hypothesis: Neurochemical effects of sleep deprivation

14. Summary

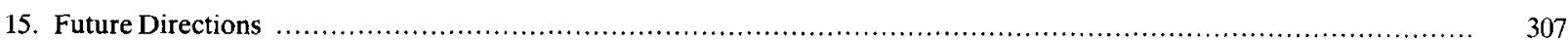

15.1. Future directions for studying cholinergic mechanisms involved in the pathophysiology of affective disorders ............. 307

15.2. Future directions: Use of normal subjects in modeling cholinergic abnormalities of depressive disorders .............................. 307

15.3. Future disorders: Defining the limits and scope of cholinergic abnormalities in the pathophysiology of affective disorders

15.4. Future directions: Defining the loci of cholinergic abnormalities involved in the pathophysiology of affective disorders

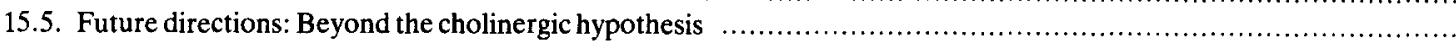

16. Summary .

Acknowledgements

Correspondence: S.C. Dilsaver, Clinical Studies Unit for Affective Disorders, Department of Psychiatry, Mental Health Research Institute, and Neuroscience Laboratory, University of Michigan, Neuroscience Lab. Building, 1103 East Huron Drive, Ann Arbor,
MI 48104-1687, U.S.A. 


\section{INTRODUCTION}

In 1972, Janowsky and colleagues ${ }^{114}$ proposed that depression and mania are hyper- and hypo-cholinergic states, respectively. The history of this article is illuminating. It was cited only 4 times between 1972 and 1975, but has now been referenced 207 times, 40 in 1985. This growing interest attests to the usefulness of the cholinergic hypothesis of depression as a construct. Researchers in both the basic and clinical sciences, including affective disorder experts, neuroendocrinologists, polysomnologists, neurochemists and pharmacologists, have found it a unifying principle as well as a rich source of testable ideas. This article reviews research directed by the cholinergic hypothesis.

Various lines of research can be classified according to the strength of the evidence they provide for the cholinergic hypothesis. Behavioral or phenomenological observations, neuroendocrine and polysomnographic responses, and the supersensitivity of affective disorders probands to cholinergic challenge lend strong support. Moderately convincing evidence comes from the utility of antimuscarinics as antidepressants, from the capacity of centrally administered cholinomimetics and anticholinesterase to reduce drive-reduction behavior and of systemically administered anticholinergic agents to increase operant responding, and from the finding that tricyclic withdrawal can produce atropine-sensitive signs and symptoms, among which is depressive symptomatology. Substances of abuse, including alcohol, cannabinoids, barbiturates, opiates, and antimuscarinic agents, either block the presynaptic release of acetyl- choline or directly block postsynaptic muscarinic receptors. Thus, substances of abuse - agents modulating mood and affect or promoting hedonia - appear to antagonize cholinergic systems, activate monoaminergic systems, or, as in the case of the stimulants, both, providing moderate or possible evidence for the cholinergic hypothesis and suggesting points of study. Preliminary studies on the effects of sleep deprivation, indicate alteration of cholinergic systems compatible with the cholinergic hypothesis. Studies on victims of suicide may also be of value, although conflicting reports on the density of muscarinic receptor binding sites in these subjects and methodological problems raise doubts with post-mortem studies. Table I lists various lines of evidence for the cholinergic hypothesis according to their strength.

\section{STRONG EVIDENCE FOR THE CHOLINERGIC HY- POTHESIS OF DEPRESSION}

Phenomenologic, polysomnographic, and neuroendocrine studies, as well as experiments measuring the sensitivity of patients with depressive disorders to cholinergic challenge relative to psychiatric and normal control subjects, provide relatively strong evidence for the hypothesis that depressive illness is associated with cholinergic overdrive or a neurobiologic characteristic that promotes its development.

\section{THE PHENOMENOLOGICAL EVIDENCE}

Centrally active anticholinesterases and cholinomimetics produce syndromes marked by dysphoria, psychomotor retardation, anergy, malaise, and a de-

\section{TABLE I}

Evidence for a cholinergic mechanism in the pathophysiology of affective disorders

Sources of evidence for the cholinergic hypothesis of depression classified according to strength of support which they accord. Some of these sources may eventually be of considerable support and currently have heuristic value because they promise to foster clinical and basic inquiry. Thus, current strength of support is a limited measure in the categorization of these 10 items.

\section{Degree of Evidence}

\begin{tabular}{|c|c|c|}
\hline Strong & Moderate & Possible \\
\hline 1. Behavioral/Phenomenological & 5. Antimuscarinics have antidrepessant properties & 9. Sleep deprivation data \\
\hline 2. Neuroendocrine & 6. Drive reduction studies & 10. Postmortem studies \\
\hline 3. Polysomnographic & 7. Tricyclic, anticholinergic withdrawal phenomena & \\
\hline $\begin{array}{l}\text { 4. Affective disorder probands are } \\
\text { supersensitive to cholinergic agents }\end{array}$ & 8. Drug abuse data & \\
\hline
\end{tabular}


sire but inability to sleep $6,15,30,58,82,113,115,116,118,119$, 204.209 . Grob et al.$^{90}$ reported induction of depressive symptomatology by diisopropylflurophosphonate (DFP) nearly 40 years ago. Intramuscular administration of 1-2 mg resulted in excessive dreaming, insomnia, jitteriness, restlessness, increased tension, lability, subjective tremulousness, and confusion. Neostigmine did not cause these symptoms in 60 subjects. Rowntree et al. ${ }^{213}$ gave DFP to normal subjects for 7 days, $1 \mathrm{mg}$ on Day 1 of the experiment and $2 \mathrm{mg}$ on days 2-7. Depression, irritability, lassitude, apathy, decreased motor activity, tension, restlessness, emotional lability, and insomnia followed. Gershon and Shaw ${ }^{82}$ observed psychiatric sequelae of organophosphate poisoning in 16 subjects. Dysphoria, irritability, nightmares, extreme fatigue, memory and concentration impairment, and psychomotor retardation or agitation were common symptoms, all of which responded to atropine and cessation of exposure to the anticholinesterase. Bowers et al ${ }^{15}$ gave organophosphate EA-1701, being studied for military purposes, to 93 normal subjects. Thirty-seven exhibited a decline in whole blood cholinesterase activity to $10-40 \%$ of their baseline. Fifty-seven percent $(57 \%)$ in this group experienced depressed mood, fatigue, weakness, slowed speech, and subjective motoric slowing. 'Jitteriness' and sleep disturbance were frequent. Sleep disturbance was marked by insomia and excessive, vivid, and frightening dreams.

Physostigmine, a reversible anticholinesterase, produces depressive-like symptomatology $y^{112,113,115-}$ $119,204,205,209,227,266$. Janowsky et al. ${ }^{116}$ studied effects of this drug in 6 bipolar patients while they were manic. Placebo injections were followed by infusion of neostigmine or physostigmine. The latter was given in $0.25 \mathrm{mg}$ or $0.5 \mathrm{mg}$ doses every $5 \mathrm{~min}$, until either behavioral change occurred or a total dose of $3.0 \mathrm{mg}$ was reached. Response was monitored using a modified version of the Beigel-Murphy Manic Rating ${ }^{11}$ and the Bunney-Hamburg Scales ${ }^{23}$. The anticholinesterase induced significant decreases in the global manic intensity score and on the manic euphoriagrandiosity, 'is talking', 'is active', 'jumps from one subject to another', and 'looks happy and cheerful' subscales of the Beigel-Murphy scale ${ }^{11}$. The Bunney-Hamburg scale ${ }^{23}$ score more than doubled (indicating decreased manic symptoms and increaed depression). Patients were also rated on several 0-5 point scales, broadly measuring the dimension of behavioral inhibition-activation. Scores increased on many of these scales, including (1) lethargy, (2) slowed thoughts, (3) 'wants to say nothing' (4) withdrawal, (5) apathy, (6) anergy, (7) 'feels drained', (8) hypoactivity, (9) 'lacks thoughts', (10) motoric retardation, (11) emotionally withdrawn, and decreased on (12) cheerfulness, (13) friendliness, (14) interacting', (15) talkativeness. In summary, symptoms of mania diminished.

El-Yousef et al. ${ }^{58}$ studied effects of physostigmine on two chronic abusers of marijuana. This anticholinesterase counteracted the marijuana 'high state' and produced a profound depression in both. The depressive syndrome included feelings of uselessness, hopelessness, apathy, sadness, decreased thoughts and verbalizations, dysphoria, suicidal ideation, and extreme psychomotor retardation lasting $10 \mathrm{~min}$ in one subject and $30 \mathrm{~min}$ in the other. One subject's distress was aborted by atropine sulfate $1 \mathrm{mg}$, i.v. Dilsaver et al. ${ }^{44}$ reported a similar syndrome which was marked by severe dysphoria, psychomotor retardation, suicidal thoughts, anorexia and anxiety following discontinuation of thiothixene and benztropine in a chronic cannabis smoker. This syndrome also responded to high doses of atropine $(1.2 \mathrm{mg}$, orally, every 4 hours). These uncontrolled observations suggest the possibility that agents in marijuana supersensitize central cholinergic systems.

Animal data also support this hypothesis. Rosenblatt et al. ${ }^{211}$ reported that treatment of rat with marijuana potentiated the toxicity of physostigmine. Biochemical studies are corroborative and suggest a possible mechanism. Kumbarachi and Nastok ${ }^{153}$ found that $4^{9}$-THC (tetrahydrocannabinol) caused a decrease in the quantal release of acetylcholine at neuromuscular junctions, and, with protracted application, complete blockade. Yoshimura et al. ${ }^{271}$ observed increased in striatal and amygdaloid acetylcholine content in response to treatment with $\Delta^{9}$ THC. This finding is consistent with a drug-induced increase in acetylcholine content due to diminished acetylcholine release. Layman and Milton ${ }^{160}$ demonstrated that cannabinoids do in fact reduce acetylcholine release at muscarinic junctions. Drugs significantly interfering with the quantal release of acetylcholine are apt to denervate postsynaptic neurons pharmacologically, thereby producing up-regulation 
and supersensitivity of cholinergic system. This phenomenon could account for the reactions ohserved by El Yousef et al. ${ }^{58}$ and Dilsaver and colleagues ${ }^{44}$.

Janowsky et al. ${ }^{118}$ studied the effects of physostigmine in 16 patients with affective and schizoaffective disorders and in 6 schizophrenics without affective symptoms under double blind conditions. Patients with an 'affective component' showed significant increases in depressed mood and a 'generalized inhibitory state' consisting of lethargy and emotional withdrawal after physostigmine infusion. Apathy, anergy, psychomotor retardation, fatigue, and decreases in thought production, social interaction, talkativeness, and friendliness were also found. This cholino- lytic sensitive syndrome resembled the "psychomotor component of retarded depression'.

Janowsky et al. ${ }^{115}$ observed that physostigmine and methylphenidate act antagonistically in both humans ${ }^{112}$ and animals. This finding is consistent with the hypothesis that depression and mania involve an imbalance of the cholinergic and adrenergic systems. Physostigmine also antagonized manic symptomatology in 12 bipolar and 24 schizophrenic patients when infused in $0.5 \mathrm{mg}$ doses until either inhibition occurred or a total dose of $2.5 \mathrm{mg}$ was reached ${ }^{116}$. Several 0-5 point activation-inhibition scales, a modification of the Beigel-Murphy manic-state rating scale $^{11}$, and independent global ratings for irritabili-

Cholinergic-Monoaminergic Interaction Theory

Monoaminergic Nuclei Activate RAS

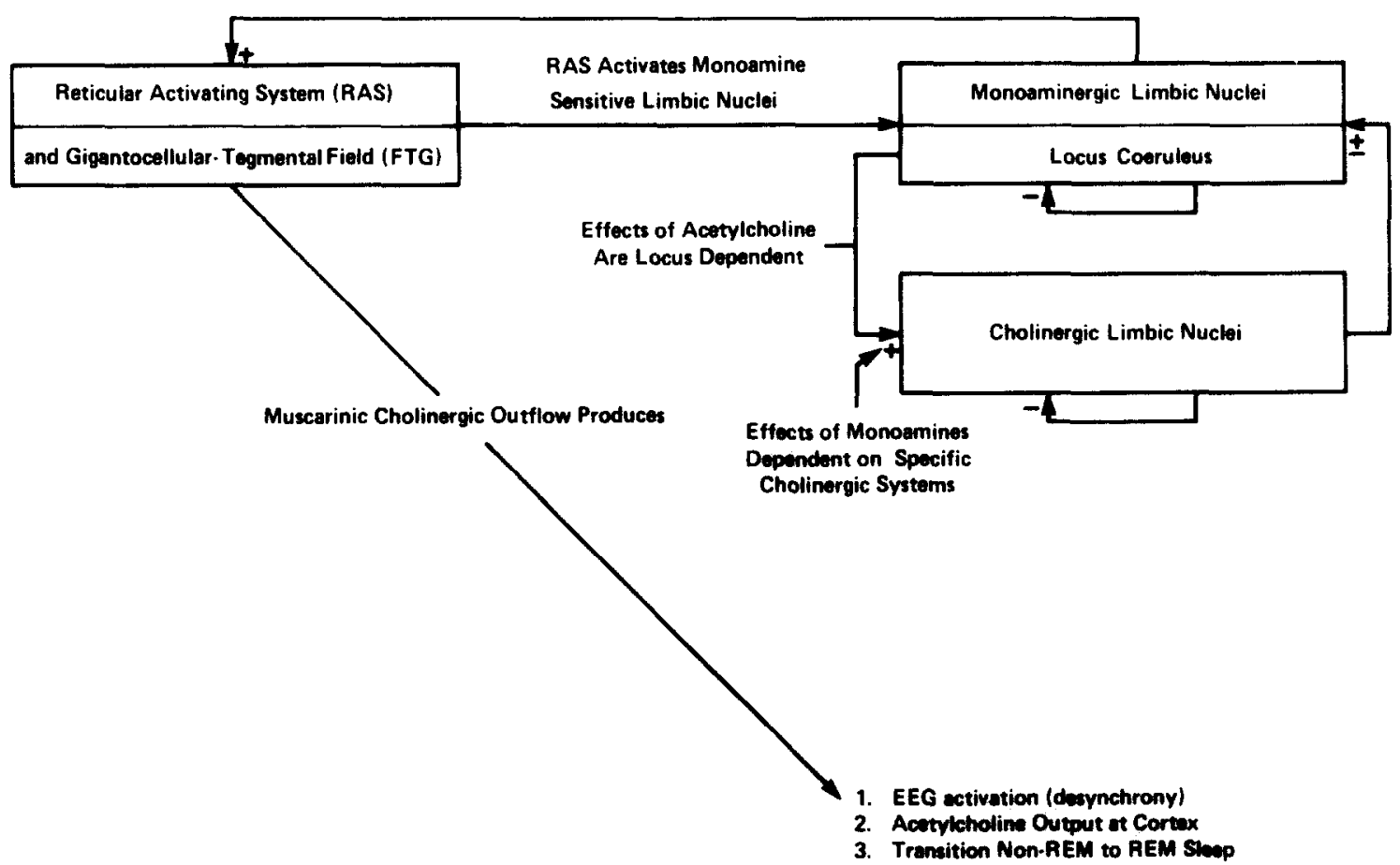

Fig. 1. This presents elements of the Cholinergic-Monoaminergic Interaction Theory. The reticular activating system (RAS) interacts with limbic aminergic nuclei involved in affecting behavioral arousal. Cholinergic pontine neurons (FTG) interact with adrenergic neurons of the locus coeruleus similarly in the regulation of REM-non-REM transitions. The RAS and FTG both produce cholinergic outflow and the output of acetylcholine at the cortex. This is essential to development of the electrocortical desynchrony which normally accompanies behavioral arousal and the physiology of REM-non-REM shifts. Cholinergic limbic neurons interact with monoaminergic cells to regulate and modulate mood, affect, neuroendocrine functions, psychomotor status and other variables relevant to affective and substance abuse disorders. These systems are auto- and inter-regulated. Thus, the value of monoaminergic variables is a function of the value of variables describing the cholinergic limbic nuclei and vice-versa. Please see text for further explanation. 
ty, dysphoria, hostility, anger, wanting to be alone, crying, sadness, sleepiness, unusual thought content, conceptual disorganization, and blunted affect were employed. The anticholinesterase once again produced 'symptoms characteristic of psychomotor inhibition" in both the schizophrenic and bipolar groups. Methylphenidate had opposite effects, which were either prevented or reversed by physostigmine.

Carroll et al ${ }^{30}$ gave up to $4.2 \mathrm{mg}$ of i.v. physostigmine to two manic subjects and to another with corticosteroid-induced psychosis with manic and confusional features. All were psychotic. The investigators concluded that physostigmine non-specifically affects psychomotor activity and produces anergia without altering manic thought disorder, i.e., the manic thought disorder has a mechanism distinct from the psychomotor disturbance characterizing mania, though the former may depend on the latter for expression.

Shopsin et al. ${ }^{227}$ studied the effects of up to $6 \mathrm{mg}$ of i.v. physostigmine in 3 manic patients using a doubleblind design. Sedation, drowsiness, a desire but inability to sleep, confusion, difficulty concentrating, and reductions in spontaneous verbal production occurred. Provocation sometimes resulted in a fullblown display of manic ideation. The authors concluded that the delusional elements of manic psychopathology were not fundamentally altered.

In contrast to Shopsin et al. ${ }^{227}$ and Carroll et al. ${ }^{30}$, Davis and colleagues ${ }^{36}$ concluded that physostigmine produced genuine depressive symptomatology and has antimanic properties. They catalogued the effects of $4 \mathrm{mg}$ of physostigmine given i.v. at a constant rate over 60 min to 8 manic subjects, using visual analogue and Pettersen ${ }^{196}$ mania scales to measure the intensity of symptoms. Six patients exhibited shifts from a manic state to one characteristic of significant depression. Visual analogue and Pettersen ${ }^{196}$ mania scales were used to measure the intensity of symptoms. The possibility that anergia or nausea and vomiting altered expression of clinical features integral to mania without modifying manic ideation was explored. Subjects reported slowed thoughts, difficulty concentrating, and occasional dizziness after receiving about $2 \mathrm{mg}$ of physostigmine. Most experienced depressive cognition and dysphoria after receiving 3$4 \mathrm{mg}$ of the drug, and a few even became tearful. Onset of nausea, vomiting, and anergia generally pre- ceded onset of dysphoria.

Effects of physostigmine on mood in normal subjects is a topic of debate. Davis et al. ${ }^{34,35}$ infused $3 \mathrm{mg}$ of physostigmine or placebo into groups of 13 and 10 normal subjects, respectively. A 'physostigmine syndrome' of decreased speech, slowed thoughts, mild sedation, expressionless faces, nausea, and decreased spontaneous motor activity was evident after subjects received 1.5-2.0 mg, but placebo and physostigmine groups did not differ significantly. Two physostigmine but no placebo subjects, however, became tearful and depressed. The investigators later learned one of the physostigmine-sensitive individuals had a history of significant premenstrual depression and the other of marijuana abuse. Oppenheim et al. ${ }^{189}$ studied the effects of a bolus i.v. injection of $1.25-2 \mathrm{mg}$ of physostigmine on mood in 5 normal subjects, using the modification of the BunneyHamburg $^{23}$ scale adopted by Janowsky et al. ${ }^{115,116}$. These subjects developed psychomotor retardation, but it was uncertain whether they experienced genuine dysphoria. Thus, although procedures used to identify and quantitate variables and the power of statistical tests used to analyze data may have been insufficient to identify differences between the physostigmine and placebo conditions in some studies of normal subjects, the effects of physostigmine in normals, if they exist, are subtle.

How normal subjects respond to pharmacologically induced central cholinergic overdrive, however, is not necessarily germane to the question of whether central cholinergic overdrive plays a role in the genesis of affective disorders. Moreover, subjects developing depressed mood in response to centrally acting cholinergic agents may possess pre-existing aberrations at central cholinergic loci resembling those of affective disorder patients and chronic abusers of marijuana; i.e., these aberrations may not be specific to affective disease. Such disturbances may permissively promote development of affective disorders; alternatively, they could be a factor or one of a group of factors necessary but not sufficient to produce affective illness. It would therefore seem wise to screen subjects not only for personal affective pathology but also for illness in first-degree relatives, on the supposition that such defects have a hereditary component.

The effect of cholinergic challenge in normal vs affectively ill subjects using an ABA design (with sub- 
jects as their own controls) may provide additional clues to the contribution of cholinergic overdrive to depressive symptomatology. Risch et al. ${ }^{204}$ investigated the effects of physostigmine on mood and affect in 9 normal subjects screened for absence of personal and family history of affective disorders and marijuana use. This study differed from those done previously in using self-reports of depressed mood to complement investigator completed ratings. Subjects received i.v. infusions of $0.022 \mathrm{mg} / \mathrm{kg}$ of physostigmine salicylate or saline in a randomized, doubleblind, counterbalanced design. The anticholinesterase-produced increases in depressive-like symptoms including decreased speech, sedation, lack of facial expression, reduced motor activity, dysphoria and depressive cognition. Self-reports of such symptoms began within 10 to $20 \mathrm{~min}$ of infusion and before the onset of nausea and vomiting. These investigators concluded that participants in earlier studies ${ }^{34.35,271}$ may have developed depressed mood but failed to report it because of physostigmine-induced psychomotor retardation, withdrawal, and reduction in verbalization. Moreover, Davis et al. ${ }^{34.35}$ rated subjects 30-45 min after the physostigmine infusion, when most symptomatology may have resolved. In addition, rater blindness was not addressed in the earlier reports ${ }^{35.36}$. Finally, Risch et al. ${ }^{204}$ used higher doses of physostigmine or a shorter infusion time than did previous investigators.

Two studies suggest that affective disorder patients show exaggerated mood changes, compared to psychiatric control subjects, in response to physostigmine challenge. Janowsky et al. ${ }^{118}$ studied 37 drugfree patients diagnosed by Research Diagnostic Criteria (RDC) $)^{189}$ to test the hypothesis that patients with depressive disorders are more sensitive to physostigmine than other psychiatric patients. Subjects were 17 affective disorder patients, 10 of whom had major depressive disorder and 7 mania, and a control group of 20 patients with 'other' psychiatric diagnoses ( 4 with schizoaffective disorder, 12 detoxi-: fied alcoholics, two with histories of past drug abuse, and two with miscellaneous psychiatric disorders). Subjects received $0.022 \mathrm{mg} / \mathrm{kg}$ of physostigmine salicylate by i.v. infusion over $10 \mathrm{~min}$ on one day and placebo on another. In comparison with the control group, affective disorder patients exhibited exaggerated responses on the Brief Psychiatric Rating Scale
$(B P R S)^{244}$ depression subscale, investigator completed ratings of activation, dysphoria, inhibition. subject completed ratings of inhibition, and the Profile of Mood States (POMS) ${ }^{35}$ subscales of tension-anxiety, depression-dejection, anger-hostility, fatigue, and decrease in friendliness. Risch et al. ${ }^{93}$, using the same methodology on 14 affective disorder subjects and 15 patients with 'other' diagnoses, confirmed the findings of Janowsky et al. ${ }^{11 x}$.

In summary, anticholinesterases appear capable of producing depressive syndromes in susceptible subjects. Physostigmine has been particularly useful in studying the role of cholinergic systems in the regulation of mood and affect. Cholinergic manipulations suggest that even normal subjects can experience dysphoria and other symptoms of melancholia with pharmacologic induction of central cholinergic overdrive. The strength of effect, however, is greater in affective disorder subjects, who appear to be supersensitive to physostigmine challenge.

\section{NEUROENDOCRINE DATA}

Hypercortisolemia and unresponsiveness of the limbic-hypothalamic-pituitary-adrenal (LHPA) axis to feedback inhibition are confirmed features of depressive illness ${ }^{106 \cdot 107,216,220}$. The discovery of these neuroendocrine abnormalities in melancholia, however, was preceded by extensive study of regulatory mechanisms of neuroendocrine function in normal animals. These included in vitro ${ }^{17,19,77,100,127}$ studies of the release of corticotropin releasing factor (CRF) from explanted hypothalamus ${ }^{78,91,95,96.147,168,178,179,}$ 193,246 and in vivo studies of the physiology of the LHPA axis. One paradigm involved in vitro release of CRF from hypothalamic explants in response to various agonists. In general, catecholamines were found to generally be inhibitory and muscarinic agonists stimulatory of CRF secretion, both in vitro and in vivo $^{78,91,96,147,178,246}$. In vivo studies also indicated a muscarinic mechanism in the release of CRF and a noradrenergic mechanism in the inhibition of CRF

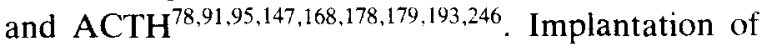
atropine crystals into the anterior hypothalamus inhibits the release of vasopressin, ACTH, and $\mathrm{CRF}^{96,135,149}$ and the adrenocortical response to surgical stress under ether anesthesia or to injection of arginine vasopressin. Krieger and Krieger ${ }^{14 y}$ found 
that atropine aborts the anticipated circadian rise in 17-hydroxycorticosteroid plasma concentration in cats. Kaplanski and Smelik ${ }^{135}$ reported implantation of atropine crystals into the anterior hypothalamus inhibited stress-induced ACTH secretion. These findings suggest that acetylcholine activates the LHPA axis under several conditions (baseline, stress, in response to diurnal changes, etc.).

Regulation of the LHPA axis involves interactions among several neurotransmitter systems. Janowsky et al. ${ }^{120}$, after reviewing the evidence, concluded that norepinephrine, endogenous opioids, and $\gamma$-aminobutyric acid tend to inhibit whereas serotonin and acetylcholine tend to activate the axis. This simplification, however, is intended only as a guide. Serotonin, for instance, acts at several points along the LHPA axis ${ }^{120,148,259}$. Implantation of serotonin crystals at certain central loci induces elevated basal corticosterone levels in guinea pigs ${ }^{259}$ (i.e. activation of the axis) but inhibits ACTH release when placed in the dorsal hippocampus and amygdala ${ }^{148}$. Moreover, its effects are contingent upon the state of the organism - that is, whether the animal is at baseline, subject to a stress, anesthetized, or at one point in its circadian cycle rather than another. Serotonergic mechanisms may in fact play a role in regulating circadian change in LHPA function, which are 'contradictory'. For example, Parachlorphenylanine (PCPA)-induced depletion of brain serotonin elevates the morning decrement and prevents the evening rise in plasma corticosterone levels in unstressed animals ${ }^{150,259}$.

Physostigmine releases $\beta$-endorphin in normal humans ${ }^{31,49,203,206,207,210}$, but depressed patients show

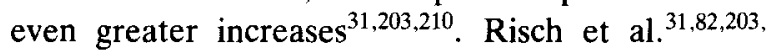
209,210 demonstrated that affective disorder patients exhibit concurrent behavioral and neuroendocrine hyperresponsiveness to physostigmine in comparison with normal and psychiatric control subjects. Physostigmine infusion also caused significantly greater plasma prolactin elevation in 14 affective disorder patients than in 15 non-affective psychiatric patients ${ }^{120}$. These increases correlated with cholinergic overdrive and with increases in negative affect when all 29 patients were grouped. Negative-affect was also correlated with the plasma $\beta$-endorphin concentration in control subjects. However, patient subgroups could not be compared with the normal sub- jects previously studied by these investigators because the former received $33 \%$ less physostigmine. The authors suggest that the correlation of increases in negative affect with prolactin and plasma $\beta$-endorphin elevations following physostigmine infusion point to simultaneous involvement of central neurochemical mechanisms regulating affect, $\beta$-endorphin, and prolactin secretion. It is also possible, however, that these phenomena reflect a singe mechanism or result from two or more cholinergic systems operating in parallel.

Physostigmine infusion can cause escape from dexamethasone suppression ${ }^{31,49}$, a marker of the depressed state ${ }^{29}$. Davis and Davis ${ }^{35}$, questioning the specificity of this response, administered placebo and $1-2.0 \mathrm{mg}$ of physostigmine at a constant rate over $1 \mathrm{~h}$ to 17 subjects. They concluded it is not possible to identify an anterior pituitary hormone whose plasma level parallels changes in central cholinergic activity. The lowest dose of physostigmine did not alter plasma cortisol level and larger doses produced a 'stress response' marked by nausea and by elevations of cortisol, prolactin, and growth hormone concentrations. They proposed that nausea non-specifically elevated peripheral cortisol, prolactin, and growth hormone concentrations.

Carroll et al..$^{31}$ gave oral syrup of ipecuacuanha to a male volunteer in order to test 'stress response hypothesis'. The subject experienced 'significant' nausea and pallor and vomited twice. A month later, he received a physostigmine infusion regulated so as to avoid nausea. Both experiments were conducted after dexamethasone was administered (the night prior to the experimental manipulation) $23.00-23.30 \mathrm{~h}$, according to the standard protocol of the Michigan group ${ }^{29}$. The emetic did not cause escape of plasma cortisol from dexamethasone-induced suppression, despite having caused nausea and vomiting. Physostigmine, however, caused a major rise in plasma cortisol concentration without producing nausea. The subject rated the physostigmine experiment as being less noxious than the ipecuacuanha study. In a related study, methylscopolamine was given to block the peripheral effects of physostigmine. They administered $0.5-1.0 \mathrm{mg}$ of this agent i.v. using a pulse rate of $100 / \mathrm{min}$ as an endpoint. Physostigmine nonetheless produced elevation of plasma cortisol. Atropine pretreatment, by contrast, prevented the anticholi- 
nesterase-induced escape from dexamethasone suppression. These findings suggest that physostigmine activates a central cholinergic mechanism that in turn activates the LHPA axis and argues against the "nonspecific stress-response' hypothesis.

Doerr and Berger ${ }^{49}$ also studied the effects of physostigmine on the LHPA axis during dexamethasone suppression testing. Twenty-three normal subjects were given a $1.5 \mathrm{mg}$ challenge of dexamethasone at $23.00 \mathrm{~h}$ on Day 1: Methylscopolamine, 0.5 $\mathrm{mg}$, was given at $15.30 \mathrm{~h}$ on Day 2 to block peripheral affects of physostigmine. Escape was defined as a rise in plasma cortisol concentration to $\geqslant 5 \mu \mathrm{g} / \mathrm{dl}$ or more at $16.00 \mathrm{~h}$ on Day 2. Three subjects escaped after receiving $1 \mathrm{mg}$ of the anticholinesterase, only one of these 3 experienced nausea. Ten subjects not responding to $1.0 \mathrm{mg}$ physostigmine failed to suppress when challenged one or two weeks later with $1.5 \mathrm{mg}$ of the anticholinesterase given by a slow infusion. Two of the remaining 10 suppressors escaped when $2.0 \mathrm{mg}$ of physostigmine was given. Nausea, dizziness, and other symptoms characteristic of cholinergic overdrive were more frequent at the higher doses. These data lend further support to the hypothesis that physostigmine activates a central muscarinic mechanism, thus causing escape from dexamethasone suppression.

\subsection{Multilevel evaluation of the LHPA axis}

Developments in molecular biochemistry now allow assessment of the LHPA axis at all levels. Peptides formed by the cleavage of a 31,000 dalton molecule, pro-opiomelanocortin, are co-released and interact with one another along the axis ${ }^{2,61,92,130,131}$. Selective cleavage of this molecule results in formation of ACTH and $\beta$-endorphin, which are thus co-released and co-regulated peptides. This knowledge has stimulated new questions that can be posed in clinical studies of LHPA function in patients with affective disorders.

Drs. Stanley Watson and Huda Akil at Michigan, Alan Rosenbaum, formerly of Henry Ford Hospital in Detroit, and Dennis Charney of Yale University studied the release of cortisol, $\beta$-endorphin/ $\beta$-lipotropin at baseline and after dexamethasone challenge in 47 patients with major depressive disorder, endogenous subtype and 16 controls with other psychiatric illnesses (personal communication from Dr. Stanley
Watson). Subjects were diagnosed using the SADS $^{244}$ and RDC $^{243}$. Pre- and post-dexamethasone plasma cortisol and $\beta$-endorphin/ $\beta$-lipotropin plasma levels were measured in samples collected at around $16.00 \mathrm{~h}$ in all subjects. Thirty-four depressed patients and 12 controls had samples collected at 20 -min intervals between 15.30 and $16.30 \mathrm{~h}$ to allow determination of intra-subject assay variance. Dexamethasone challenge was associated with lower $\beta$-endorphin $/ \beta$ lipotropin levels, relative to baseline, in all but one control subject. Two fmol $\beta$-endorphin/ $\beta$-lipotrophin $/ \mathrm{ml}$, the post-dexamethasone plasma $\beta$-endorphin $/ \beta$-lipotropin concentration maximizing predictive value for depression ${ }^{75,76}$, was selected as a cutpoint. Ninety-five percent $(95 \%)$ of the control subjects, compared to $41 \%$ of the depressives, demonstrated a decline or suppression of $\beta$-endorphin/ $\beta$-lipotropin plasma concentration to below $2 \mathrm{fmol} / \mathrm{ml}$ $\left(10^{-18} / \mathrm{ml}\right)$ on dexamethasone challenge. Twenty-two percent of the experimental group demonstrated non-suppression of cortisol release alone, and $39 \%$ showed non-suppression of $\beta$-endorphin/ $\beta$-lipotropin secretion but suppression of cortisol; $28 \%$ were suppressive of both, and $11 \%$ of neither $\beta$-endorphin/ $\beta$-lipotropin nor cortisol.

Is there a cholinergic defect at the limbic, hypothalamic, or pituitary level? The relationship of ACTH to $\beta$-endorphin $\beta$-lipotropin and plasma cortisol suggests several sites for studying the effects of cholinergic challenge. Risch et al. ${ }^{210}$ documented a stoichiometric relationship between $\mathrm{ACTH}$ and $\beta$-endorphin immunoreactivity thus indicating co-release in humans in response to central cholinergic stimulation. They also showed that mood and behavioral changes produced by physostigmine are accompanied by elevations in both plasma $\beta$-endorphin and cortisol concentrations $\mathrm{s}^{203,204,207.209}$. These findings suggest that physostigmine acts on central cholinergic mechanisms or relevance to affective disorders research.

Measurements at fixed intervals of plasma cortisol, ACTH, and $\beta$-endorphin $/ \beta$-lipotropin immunoreactivity in normal human subjects and affective disorder patients in response to different doses of physostigmine infused at a constant rate would be of particular interest. If dose-response curves for the release of $\beta$-endorphin and $\mathrm{ACTH}$ in response to pharmacologically induced central cholinergic overdrive in affectively ill patients fell to the left of those 
of normal controls, the hypothesis of cholinergic supersensitivity in depression would receive definitive confirmation.

\section{POLYSOMNOGRAPHIC DATA}

Polysomnographic abnormalities most frequently observed in patients with depressive disorders are (1) disturbances of sleep continuity or diminished sleep efficiency, (2) a reduction in $\Delta$ or (slow wave) sleep, (3) shortened REM latency, and (4) increased REM activity and density $62,66,67,83,84,154,155,157$. These abnormalities of primary ${ }^{97}$ or major depressive disorder, endogenous subtype ${ }^{243}$ can be produced by cholinergic overdrive $\mathrm{e}^{98.101-105,122,128,129,136-139,169,170,232}$ and suppressed by cholinoceptor blockade ${ }^{221,255}$.

Regulation of both the tonic (intra-stage) and phasic (having to do with the relationship of sleep stages to one another) aspects of sleep involves cholinergic mechanisms ${ }^{61.67 .83,84.98 .101-105.122,128,129,136-139, ~}$ 154,169,170.232. Anticholinesterases produce subjective disturbances of sleep continuity and vivid, terrifying dreams ${ }^{15,213,237}$. These complaints have polysomnographic correlates that facilitate study of cholinergic mechanisms involved in their pathophysiology.

Physostigmine tends to awaken subjects when infused during REM episodes, and injection during non-REM sleep induces transition to REM sleep ${ }^{136}$ (as defined by cholinergically mediated generalized electrocortical activation, i.e., desynchronization). Induction of REM sleep by cholinergic agents is dose- and time-dependent ${ }^{236}$. Physostigmine, $0.5 \mathrm{mg}$, given 5 or 35 min after sleep onset induced REM sleep, whereas, $1 \mathrm{mg}$ infused 35 minutes after sleep onset aroused 3 of 5 subjects. Similarly, 5 of 7 subjects awoke when $0.5 \mathrm{mg}$ physostigmine was infused during an REM episode. These observations suggest that cholinergic mechanisms have roles in mediating transitions from a state of relative behavioral and EEG inactivation (non-REM sleep) to one of increased propensity to awaken or become behaviorally active and relative EEG activation (REM sleep). Hence, sleep is characterized by epochs of relative electrical and behavioral quiescence and activation and of low and high propensities to arousal. NonREM sleep is marked by slowing and synchrony of the corticogram and REM sleep by EEG desynchronization. Thus, non-REM and REM sleep involves electrophysiological quiescence and arousal, respectively. These states, it should be noted, are on a continuum.

Gillin et al ${ }^{67}$ reported that physostigmine shortens the latency to onset of REM sleep without altering the duration of REM episodes. Sitaram et al. ${ }^{234}$ found that euthymic patients with primary affective illness demonstrated more rapid induction of REM sleep in response to cholinomimetic challenge than did control subjects, indicating phase advance of an ultradian rhythm in affective disorder subjects. A similar abnormality is thought to be involved in the etiology of the shortened REM latency observed in primary ${ }^{97}$ or endogenous depression ${ }^{244}$. Thus, polysomnographic changes induced by physostigmine suggest a phase advance resembling the derangement of the same ultradian rhythm observed in depressive disease ${ }^{232}$.

Concurrent induction of cholinergic overdrive and monoamine depletion causes extraordinary increases in the density and duration of REM sleep. Indeed, the combination of physostigmine and reserpine was once presented as a model of REM sleep ${ }^{139}$. This model is compatible with what we know about the physiology of sleep $8,81,99,142,151,195$. Anticholinergic agents and monoamine oxidase inhibitors both powerfully suppress REM sleep, and cholinergic activation $^{81}$ antagonizes imipramine-induced suppression of REM sleep. These facts suggest that efforts to induce disturbances of REM sleep by modifying the physiology of cholinergic systems or cholinergic-monoaminergic interaction may be useful in studying the pathophysiology of sleep in the affective illnesses.

Sitaram and associates ${ }^{85,233}$ reported that scopolamine, given orally for 3 consecutive mornings and withheld on the 4th morning, was associated with decreased REM latency and increased REM index and activity on the 4 th night. Gillin et al ${ }^{85}$ applied to these data a mathematical model known to distinguish the sleep of normal and depressives and found the scopolamine-associated sleep disturbance to be indistinguishable from the sleep of patients with primary subtype ${ }^{61}$. These findings are consistent with reports that scopolamine ${ }^{12}$ and other centrally active anticholinergic agents, including tricyclics, induce muscarinic receptor up-regulation in rodent brain $^{201,250,269}$ and cardiac tissue ${ }^{180,181}$. 
A mathematical model of neuronal events regulating the phasic aspects of sleep predicts the effects of antimuscarinic administration and withdrawal. Hobson et al. ${ }^{101-105}$ and McCarley et al. ${ }^{169.170}$ suggest that regulation of the phasic aspects of sleep involves interaction between cholinergic neurons of the pontine-gigantocellular-tegmental field (FTG) and noradrenergic neurons of the locus coeruleus (LC). Within the framework of this theory ${ }^{104}$, referred to as the 'reciprocal interaction mode', neurons are labeled 'excitatory' if their depolarization affects EEG desynchronization, a correlate of behavioral arousal or excitation. The quantal release of acetylcholine by FTG neurons, ceteris paribus, increases the rate of depolarization of both FTG and LC neurons; thus, these neurons are excitatory by convention. In contrast to the cholinoceptive neurons of the FTG, noradrenergic neurons of the LC are 'inhibitory' because crescendoing of the mean rate of their discharges is associated with a decrease in EEG frequency and cortical synchronization. Electrophysiological studies indicate that the pertinent FTG neuronal population is subject to both autoregulation and regulation by a LC neuronal population. The converse is also true. The reciprocal interaction model predicts an upsurge in the mean rate of FTG neuronal discharges at the onset of each REM episode and a concurrent dip in the mean frequency of LC neuronal depolarizations. The opposite occurs at the onset of non-REM episodes.

This model has strong support. First, the temporal organization of FTG discharges with respect to the sleep-activity cycle is reciprocal to that of LC discharges. Second, each episode of REM sleep is temporally correlated with maximal mean frequency of FTG neuronal discharges. Third, each non-REM sleep period is associated with diminution of FTG activity and logarithmic build-up of LC activity. Fourth, histochemical and neurophysiological studies indicate that FTG neurons contain and release acetylcholine and are autostimulated by this neurotransmitter. Fifth, functional anatomic connections extend from the LC to FTG neurons and between LC neurons. Finally, immunohistochemical studies have disclosed varicosities staining for the presence of norepinephrine among FTG and LC neurons ${ }^{101.102,188}$

Prior to each REM episode, increased cholinergic outflow from the FTG to LC activates the latter, but the mean rate of FTG neuronal discharges increases simultaneously. This cholinergic push causes noradrenergic neurons within the $\mathrm{LC}$ to undergo a concurrent increase in autoinhibitory input. The net result is a 'turning off' of the LC neuronal population. The timing can in principle be determined because it occurs at the hypothetically quantifiable threshold of aggregate FTG activity. Cholinergic overdrive can produce disturbances of sleep staging by inappropriately activating this process.

In summary, data from naturalistic studies (occupational exposure to organophosphates) $)^{82}$, human investigations $^{83,84,170,232.234,235}$ and animal research into the physiology and neurochemistry of sleep $^{85}$. $97,98,101-105,121.122,129,136-139,1801,188,208,233,235.265$ are all consistent with the hypothesis that the pathophysiology of the sleep disturbance characterizing primary depression $^{61}$ or major depressive disorder, endogenous subtype ${ }^{243}$, involves muscarinic cholinergic system supersensitivity.

\section{SUPERSENSITIVITY OF AFFECTIVE DISORDER PATIENTS TO CHOLINERGIC CHALLENGE}

Affective disorder patients are more likely than normal and non-affectively ill psychiatric control subjects to exhibit exaggerated changes in mood, neuroendocrine, and polysomnographic parameters in response to challenge with physostigmine or arecoline. Janowsky et al ${ }^{113}$ administered i.v. physostigmine to 37 drug-free subjects diagnosed by the RDC ${ }^{243}$. This sample included 10 patients with major depres$\operatorname{sion}^{244}, 7$ with mania, 4 with schizoaffective disorder. and 14 with psychiatric illnesses without an affective component. Physostigmine, $0.022 \mathrm{mg} / \mathrm{kg}$, and placebo were infused over 10 min on different days. Affective disorder subjects had the greatest increases in self-reported measures of inhibition. The Brief Psychiatric Rating Scale (BPRS), depression subscale and the Profile of Moods States (POMS) also distinguished subjects. POMS scores of affectively ill patients showed the greatest increases in dysphoria, anxiety, hostility and fatigue. These subjects were rated as having a greater increase in depression on the BPRS depression subscale. Risch et al. ${ }^{209}$ confirmed these data using the same physostigmine dose, route of administration, and rating scales in a study of 14 subjects with major affective syndromes 
and 15 with 'non-affective' psychiatric diagnoses. Janowsky et al. recently found that affective disorder patients also exhibit exaggerated changes in autonomically regulated cardiovascular variables upon cholinergic challenge ${ }^{121}$.

Affective disorder patients have augmented neuroendocrine responses to cholinomimetic and physostigmine challenge. Physostigmine causes an increase in peripheral $\beta$-endorphin, $\mathrm{ACTH}$, and cortisol concentration in normal man both with and without concurrent dexamethasone challenge 31,49,207,210. $^{3}$. As noted above, Risch et al. ${ }^{31,207,210}$ found that patients with depressive disorders demonstrate neuroendocrine hyperesponsiveness to physostigmine, i.e., greater increases in plasma $\beta$-endorphin concentration compared to normal subjects and non-affectively ill psychiatric patients ${ }^{203,205}$. This finding implies cholinergic system supersensitivity.

Sitaram et al. ${ }^{234}$ reported that affective disorder patients in remission exhibit more rapid arecoline- or physostigmine-induced onset of REM sleep than normal controls. It is not known, however, whether these subjects would have exhibited supersensitivity prior to their first affective episode, i.e., whether it is a trait marker or effect of illness. Many polysomnographic variables, however, have a genetic (or trait) component. Webb and Campbell ${ }^{265}$ obtained onenight polysomnographic recordings for 14 identical and fraternal young adult twin pairs. Sleep onset latency, awakenings during the night, number of changes in stage of sleep, and amount of REM sleep were significantly correlated for identical but not fraternal twin pairs. Nurnberger et al. ${ }^{184}$ tested the hypothesis that sensitivity to REM induction by arecoline is a heritable trait by measuring time to onset of the second $R E M$ period $\left(\mathrm{REM}_{1}-\mathrm{REM}_{2}\right.$ interval) in twin pairs after placebo or arecoline infusion. The $\mathrm{REM}_{1}-\mathrm{REM}_{2}$ induction interval was concordant for zygosity following the infusion of cholinomimetic but not placebo. These data suggest that the supersensitive polysomnographic responses to arecoline may be heritable, i.e. a trait. Thus, it is quite possible that supersensitivity of affective disorder patients to pharmacologically induced cholinergic overdrive reflects a defect in cholinergic systems that predates development of the clinical features defining a mood disorder. This issue, however, is far from resolved.

The evidence that central cholinergic systems su- persensitivity contributes to the pathophysiology of the polysomnographic abnormalities of melancholia may provide the strongest support of the cholinergic hypothesis of depression. Perhaps the most important query for clinical investigation today is, 'Do the polysomnographic features of major depression have premorbid antecedents that would imply abiding supersensitivity of cholinergic systems?' Longitudinal study of subjects at risk can answer this question.

Study of the pathophysiology of sleep in affective disease may require a comprehensive approach, i.e., one using integrative models. Several central neurotransmitter abnormalities may be contributory. For instance, serotonergic and noradrenergic mechanisms are involved in sleep physiology, and interaction between neurotransmitter systems may be caus$\mathrm{al}^{43,46,48}$.

In conclusion, measures of behavioral, neuroendocrine, and polysomnographic variables at baseline and in response to cholinergic challenge support the hypothesis that muscarinic cholinergic system supersensitivity is either associated with or of etiologic significance in development of affective illness.

\section{MODERATE EVIDENCE FOR THE CHOLINERGIC HYPOTHESIS OF DEPRESSION}

The efficacy of antimuscarinic drugs in the treatment of depression, evidence of cholinergic-monoaminergic antagonism in regulation of reward, punishment and hedonic capacity, effects of antidepressant and antimuscarinic withdrawal on behavior, and pharmacological properties of commonly abused substances provide moderate or possible evidence for the cholinergic hypothesis. These areas of study have untapped heuristic value, and their significance may transcend the strength of evidence they accord to hypothesis.

\section{THE RESPONSE OF AFFECTIVE STATES TO ANTI- CHOLINERGIC AGENTS}

Anticholinergic agents have euphorigenic ${ }^{12,14}$, $33,131,171,199,215,238$ and antidepressant $t^{1,59,86,126,140,156 \text {. }}$ ${ }^{252,253}$ properties. Kasper et al. ${ }^{140}$ treated 10 severely depressed, hospitalized patients (classified using the International Classification of Disease $(\mathrm{ICD})^{68}$, $\mathrm{RDC}^{244}$ and Newcastle Scale ${ }^{109}$ ) with an average 
daily dose of $12 \mathrm{mg}$ of biperidin for 30 days. A significant decline in the total Hamilton Rating Scale for Depression (HRSD) $)^{94}$ score $(P<0.001)$ was observed. HRSD subscales showing significant decreases were retardation, agitation, depressed mood, initial insomnia, work and interest, and gastrointestinal symptomatology. Tislow ${ }^{253}$ reported that anticholinergic drugs had short-term usefulness in treating depressed patients. Effectiveness extending to one year was later reported ${ }^{252}$. Symptoms responding best to benzotropine, trihexyphenidyl, or biperiden were depression and anxiety in 'neurotic' and 'psychotic' patients. Jimerson and colleagues ${ }^{126}$ conducted a double-blind placebo-controlled study on the efficacy of trihexyphenidyl on the symptomatology of patients with major depression according to $\mathrm{RDC}^{243}$. Subjects were randomly assigned to an 8 week trial of up to $20 \mathrm{mg}$ of active agent or placebo. Clinical response was monitored by giving the Comprehensive Psychiatric Rating Scale (CPRS) ${ }^{28}$ weekly on a blind basis. Sample size was not mentioned. Two subjects completing the 8-week trial were reported to have 'improved dramatically', with CPRS scores declining from 29 to 13 and from 28 to 3 . One subject from each group had to be withdrawn because of poor response. Even at an average daily dose of $10 \mathrm{mg}$, trihexyphenidyl was tolerated well. It is not possible to assess the significance of this report, however, without knowing the sample size.

The earliest studies of the effectiveness of anticholinergic agents as antidepressants were flawed by failure to use standardized diagnostic criteria and clearly defined longitudinal measures of change in clinical state, but these 'old' studies did suggest that blockade of the muscarinic receptor produces antidepressant effects. English ${ }^{59}$ studied the effectiveness of N-ethyl-3-piperidyl-phenylcyclopentyl glycolate hydrochloride and N-ethyl-2-pyrrolidylmethyl-phenylcyclopentyl glycolate hydrochloride (Ditran) in a $7: 3$ ratio in treatment of 25 psychiatric patients with various diagnoses. The same included 11 patients assigned diagnoses of 'depression' (reactive, involutional, and acute agitated). Improvement was defined by the clinician's 'global impression' that the patient's condition became less severe after single or repeated doses. The author concluded that Ditran had effectiveness as an antidepressant. Although other investigators concurred that this drug is an effective anti- depressant ${ }^{1.59,86}$, some attributed its antidepressant properties a non-anticholinergic component of $\mathrm{Di}$ tran.

In conclusion, investigations suggest that agents with anticholinergic properties exert antidepressant effects, but the rigor of research design, diagnostic criteria and decision making, and measurement of outcome vary across studies. This area requires more attention.

\section{CHOLINERGICALLY INDUCED REDUCTION OF HEDONIC BEHAVIOR}

Systemically and intracerebrally administered anticholinesterases and muscarinic agonists decrease drive reduction behavior in animals $5,26,50,91,176,185-$ $187,191,217,218.245$. Though not providing a literal model of anhedonia, which after all involves subjective components, these agents do cause sufficiently stable behavioral changes to allow multiple measurements of behaviors in animals paralleling acts that would have hedonic significance in man. This strategy demands formulation of operational definitions of targeted behaviors consonant with the purposes of the investigators and dictates of the experimental situation. Such definitions must clarify the limits and nature of these behaviors, measure their crucial aspects (intensity, frequency, etc.), and assess the capacity of pharmacological manipulations to produce deviations of these variables from baseline.

Studies assessing cholinergic contributors to the physiology of hedonic capacity are plagued by unidentified sources of variance and confounding variables. First, there are many cholinergic systems (though most fibers stem from the nucleus magnus basalis). Second, effects of cholinergic agents are related to route of administration and when applied directly to brain nuclei, locus of application. Third, anatomic distinctiveness implies neither functional independence nor functional dependence. Interaction or mutual interdependence of neuronal populations may complicate experimental efforts. Olds, in his classic article ${ }^{186}$, concluded that structures underlying primary reward are located in a midline network extending from the midbrain cephalad to the hypothalamus, midline to the thalamus and thence to subcortical and cortical portions of the rhinencephalon. Those structures, he asserted, were distinct from 
those mediating the effects of primary punishing events. Neural mechanisms mediating the effects of rewarding and punishing events, however, are known to interact; rewarding events reduce sensitivity to punishment and vice versa. These anatomical and functional distinctions are essential. Application of a neurotransmitter to the reward system may induce drive-reduction behavior or reward, whereas its injection into an area mediating punishment may diminish the frequency of the same behavior or mediate the 'experience' of punishment. Caution must therefore be exercised in interpreting data from $\mathrm{mi}$ croinjection studies. Finally, the organismal response to systemic administration of a drug may represent summation of central and peripheral effects, and peripheral effects can alone alter behavior.

Domino and Olds ${ }^{50}$ studied the effects of physostigmine and neostigmine on self-stimulation behavior in rats with chronic hypothalamic electrode implantation. Doses of neostigmine equimolar to physostigmine caused significantly less reduction in and shorter periods of decreased self-stimulation behavior. Overstreet et al. ${ }^{191}$ studied the effects of systemically administered amphetamine and pilocarpine on ingestive behavior in normal and chronically DFP-treated rats. Tolerance to DFP was marked by chronically low acetylcholinesterase levels. The sympathomimetic diminished food intake in both groups equally, but the cholinomimetic failed to produce a reduction in food intake in anticholinesterase-treated animals. These observations suggested that cholinergic mechanisms are involved in inhibiting ingestive behavior and that they are subject to development of subsensitivity.

Olds and Domino ${ }^{218}$ studied the effects of subcutaneously administered nicotinic and muscarinic agents on self-stimulation in animals with electrodes implanted into the lateral-posterior hypothalamus. Physostigmine and arecoline both caused depression of this behavior that was blocked by scopolamine and augmented by mecamylamine. Methylscopolamine was clearly less effective than scopolamine in this regard. Olds ${ }^{187}$ also reported that scopolamine antagonized the inhibitory effects of physostigmine and chlorpromazine on drive reduction behavior. The chlorpromazine-scopolamine antagonism may be due to dopaminergic-cholinergic reciprocity or counterbalance that parallels nigrostriatal ${ }^{3,10}$ and mesolimbic dopaminergic-cholinergic interaction ${ }^{68}$. Decreased cholinergic tone can produce a functional increase in dopaminergic activity.

Stark and Boyd $\mathrm{d}^{25}$ found that physostigmine but not neostigmine caused a depression in the frequency of intracranial self-stimulation in dogs with electrodes implanted into the medial mamillary nucleus of the hypothalamus. Atropine but not methylatropine pretreatment prevented this. Cholinesterase inhibition paralleled the reduction in self-stimulation. This report is also consistent with the hypothesis that activation of central cholinergic mechanisms produces decreases in drive reduction or rewarded behaviors.

Russell et al. ${ }^{217,218}$ studied behavioral correlates of tolerance to DFP. Diminished acetylcholinesterase activity was used as biochemical evidence of chronic cholinergic overdrive. Food and water intake were measured during 8 days of baseline (pre-drug) observation, a DFP administration phase involving a large loading dose and periodic boosters until targeted behavioral variables returned to baseline, and a withdrawal or recovery period. DFP treatment caused both food intake to decrease, but this parameter tended to return to baseline by the third day. Water intake showed a great decrease and required 13 days to recover. DFP withdrawal caused a rebound increase in consumption. These findings are also consistent with the hypothesis that central cholinergic mechanisms subserve aspects of drive reduction behavior and are subject to modification by perturbation of cholinergic neurons. Peripheral effects of anticholinesterase treatment cannot be excluded, but one would expect a peripheral component to be nonspecific, i.e. to affect water and food consumption similarly. The longer duration required for water consumption to return to baseline, 13 days as opposed to 3 days for food intake, suggests that if a peripheral component is pertinent it pertains to the latter.

Sidman ${ }^{230}$ reported that atropine disrupted shock avoidance responses and that behaviors rarely observed (if at all) under normal circumstances result from its use. Methylatropine ineffectively or weakly mimicked atropine. He concluded that atropine inhibited a cholinergic system that antagonizes another neurotransmitter system that activates behaviors punished by shock. This hypothesis that parallels in 
theory of general behavioral (psychomotor, attentional) activation and mood regulation developed by Dilsaver and Greden ${ }^{48}$.

Carlton ${ }^{25.26}$ studied the effects of cholinoceptor blockade and amphetamine on animals conditioned to press right and left-sided levers alternately in order to be reinforced by delivery of a small quantity of milk. Scopolamine and catecholaminergic activation both resulted in perseveration. Is non-reward a type of punishment? In operant paradigms non-reward and punishment have the same effect viz. extinction. Thus, cholinergic blockade can be conceived ceteris paribus as either diminishing the intensity of punishment or making non-punishing what is normally regarded as punishment, assuming we are not dealing with a randomness caused by drug toxicity. Carlton $^{25.26}$ hypothesized that diminished cholinergic tone and increased catecholaminergic activity produce similar results and that antimuscarinics and catecholaminergic agents have additive or synergistic effects. He defined a range of 'subthreshold' reductions in cholinergic function by administering small amounts of atropine to rats trained on an operant shock-avoidance schedule. Amphetamine, 0.25 $\mathrm{mg} / \mathrm{kg}$, also failed to increase responding. Simultaneous administration of these subthreshold doses of atropine and amphetamine, however, produced marked increases in non-rewarded responses which were not predicted by study of each agent separately. The frequency of non-rewarded responses increased with the dose of amphetamine or atropine. Methylatropine did not substitute for atropine. In conclusion, a central muscarinic mechanism and monoaminergic-cholinergic interaction were implicated in the regulation of operantly conditioned shock avoidance behavior. In effect, the 'experience' of punishment was altered by the various manipulations.

Anhedonia is central to some concepts of depression $^{160}$ and a salient symptom in many patients with recurrent depressions. Animal models of hedonic impairment could therefore be quite valuable in the study of melancholia. Development of such a model, however, will not come easily. Hedonia (hedonic capacity) is a complex phenomenon. It can be defined operationally or conceptually divided into components, but it is always many things. It encompasses subjective, psychological, somatic, neurochemical, and behavioral elements. Animal models of hedonia or anhedonia are unavoidably reified approximations of a human reality. However, even limited models may allow us to test hypotheses by isolating quantifiable variables relevant to understanding human drive reduction behavior. The fact that extending generalizations or inferences drawn from animal data to the experience of man involves anthropomorphizing neither invalidates nor seriously impugns such models; it is simply evidence of limitation of models in this area.

Animal models of hedonia, which would be based on behavioral and neurochemical theories pertaining to mechanisms mediating drive reduction behavior, should be valuable in directing study of the pathophysiology of anhedonia in melancholia. Behavioral and pharmacological approaches can direct study of the neuroanatomy, neurochemistry, and neurophysiology of normal and abnormal hedonic capacity. The hypothesis that the 'central pain' associated with melancholia is associated with direct or indirect inhibitory effects on neural substrata subserving hedonia and involves aberrations of central cholinergic system is testable in animals without succumbing to reductionism.

\section{DRUG WITHDRAWAL DATA}

In general, chronic treatment with antimuscarinic agents elicits neuronal and behavioral responses characteristic of other substances that produce dependence. Antimuscarinic agents produce tolerance; the effects of withdrawal in patients being treated for Parkinson's disease or neuroleptic-induced extrapyramidal dysfunction ${ }^{108}$ include gastrointestinal distress, a flu-like syndrome, anxiety, sleep disturbance, and rebound exacerbation of motor dysfunction.

Withdrawal of tricyclic antidepressants precipitates discrete syndromes. The most common are general somatic or gastrointestinal distress accompanied by anxiety or agitation, sleep disturbance characterized by excessive and vivid dreaming and initial or middle insomnia, akathesia or parkinsonism, and psychic or behavioral activation on a continuum to mania $^{1}$. Dilsaver and associates ${ }^{46,48,176,186}$ concluded that withdrawal precipitated cholinergic overdrive accounts for most antidepressant withdrawal phenomena, though they emphasized that some are al- 
most certainly due to disturbances of cholinergicmonoaminergic interaction ${ }^{43,45-47}$. The 'cholinergic overdrive hypothesis ${ }^{43}$ is the thesis that withdrawal of antidepressants with antimuscarinic properties triggers increased cholinergic activity at critical peripheral and central loci and thence symptomatology. These loci include the gastrointestinal system and nigrostriatal, mesocortical, and mesolimbic tracts. The hypothesis is supported by the facts that (1) tricyclics are muscarinic antagonists ${ }^{4,13,202,241,247,254}$, (2) antimuscarinic agents produce tolerance and, upon withdrawal, hyperexcitability of cholinergic systems $\mathrm{s}^{40,73,110,228}$, (3) antidepressant withdrawal symptoms respond to anticholinergic drugs, and (4) amitriptyline and desipramine produce cholinergic system up-regulation and supersensitivity in rodent brain and heart, respectively.

Tricyclic-induced supersensitivity of cholinergic systems is evidenced by differences in pupillary responsivity to a cholinomimetic before, 7 days after, and 21 days after starting desipramine in depressed subjects ${ }^{40,228}$. Twenty-one days of desipramine treatment, but not 7 , were associated with an enhanced miotic response to pilocarpine. Scopolamine causes an increased density of muscarinic receptor binding sites in rat hippocampus. Many other investigators have confirmed this effect of classic antimuscarinics. Rehavi et al. ${ }^{201}$ reported that 21 days of amitriptyline administration, but not 7 , produced an elevation in the density of muscarinic receptor ligand binding sites in mouse forebrain. Goldman and Erickson ${ }^{86}$ also observed amitriptyline produced up-regulation of muscarinic receptors in rat brain. Normura et al. ${ }^{180}$ reported that desipramine, $10 \mathrm{mg} / \mathrm{kg}$ twice daily for 10 days, induced a significant increase in maximum muscarinic radioligand binding sites in rat myocardium. These investigators also found that desipramine induced supersensitive physiological and biochemical responsiveness of the myocardium to acetylcholine. Dilsaver and Snider ${ }^{41}$ recently observed that chronic tricyclic treatment produced supersensitivity to oxotremorine in rats as inferred from differences in cholinomimetic-induced hypothermia before and after amitriptyline treatment.

The 'cholinergic overdrive hypothesis' is subject to examination using neuroendocrine strategies. We predicted, for example, antidepressant withdrawal would produce non-suppression to dexamethasone challenge ${ }^{42}$. To test this hypothesis, we assessed the integrity of the LHPA axis by measuring its capacity to respond appropriately to dexamethasone challenge before and at one or more points after antidepressant withdrawal. Post-dexamethasone plasma cortisol concentrations and $\mathrm{HRSD}^{94}$ scores were serially monitored in 15 subjects being withdrawn from tricyclics or a tetracyclic (maprotiline) during the first two weeks of hospitalization on the Clinical Studies Unit for Affective Disorders at the University of Michigan (CSU). A control group was comprised of 9 endogenously ${ }^{41,42}$ depressed patients who were drug-free on the CSU. 'Drug-free status' is defined as 14 or more days removed since receiving the last dose of psychotropic medication. Control subjects had become drug-free within 4 days of admission. All subjects were inpatients and diagnosed using the $\mathrm{SADS}^{244}$ and $\mathrm{RDC}^{243}$ as having major depression, endogenous subtype.

Post-dexamethasone plasma cortisol levels were significantly elevated during the drug-withdrawal phase. Twelve subjects had higher post-dexamethasone plasma cortisol levels during the withdrawal than during the post-withdrawal phase. Ten of 14 (71.4\%) of these subjects had a positive DST during the 14-day withdrawal phase, compared to 2 of 9 (22.2\%) control subjects ( $P=0.03$, Fischer's exact) during the first two weeks of their hospitalization. These differences in the frequencies of positive DSTs and absolute post-dexamethasone plasma cortisol levels did not persist after the withdrawal subjects became drug-free.

No differences in $\mathrm{HRSD}^{94}$ scores were detected at baseline or over the course of the study, nor did weight change differ significantly between groups. This retrospective study did not establish the role of antidepressant withdrawal-induced cholinergic overdrive in the generation of abnormal responses to dexamethasone challenge. It was, however, consistent with hypotheses regarding effects of antidepressants on cholinergic systems. Effects of antidepressant withdrawal on the LHPA axis must now be studied using a design involving random assignment of subjects to multiple daily doses of a tricyclic, antimuscarinic and placebo.

In principle, medical treatments or recreational drugs that supersensitize muscarinic cholinergic systems should increase the probability of a subject's de- 
veloping depressive episodes. Marijuana may be a good example. Cannabis produces tachycardia, dry mouth, suppression of REM sleep, a trend toward slowing of the electrocorticogram, short-term memory deficiencies, and other effects characteristic of centrally active anticholinergic drugs ${ }^{54,111}$. I ayman and Milton ${ }^{160}$ verified that cannabinoids decrease the release of acetylcholine at muscarinic junctions. Assuming sufficient potency, dose, and duration of treatment, postsynaptic muscarinic receptor up-regulation and cholinergic system supersensitivity would be expected to occur.

Animal studies and clinical reports are consistent with the hypothesis that cannabinoids render central cholinergic systems supersensitive. El-Yousef et al. ${ }^{58}$, (Cf. Section 3) found that chronically intoxicated marijuana users developed profound depression when challenged with physostigmine. Furthermore, $\Delta^{9}$-THC potentiates the toxicity of physostigmine in rats. Dilsaver et al ${ }^{44}$ observed a withdrawalinduced state of cholinergic overdrive in an 18-yearold woman who discontinued thiothixene and benzotropine abruptly. Both of these psychotropics are antimuscarinic ${ }^{9}$. We later learned that she had chronically abused marijuana. Though she lacked a personal and family history of a depressive disorder, she developed a severe depressive syndrome with definite 'anticholinesterase-like' symptomatology. Symptoms included tearfulness, agitation, 'extreme muscle tenseness', behavioral withdrawal, apathy, decreased verbal production, apprehensiveness, psychomotor retardation, severe insomnia or near sleeplessness for about 3 days, slowing of thought processes, poor self-care, fear of losing her mind, nausea, vomiting, anorexia, and diarrhea - all features of endogenous depression. This syndrome responded to high dose oral atropine sulfate, $1.2 \mathrm{mg}$ every $4 \mathrm{~h}$, without development of noteworthy side-effects. We concluded that cannabis abuse induced muscarinic cholinergic system supersensitivity and that psychotropic withdrawal triggered cholinergic overdrive.

In conclusion, drugs blocking postsynaptic muscarinic receptors (belladonna alkaloids, synthetic agents resembling atropine, tricyclics, or diminishing the release of acetylcholine centrally (opiates, cannabinoids, ethanol, barbiturates) are apt to produce central cholinergic system up-regulation and supersensitivity. These agents might be safely used to model aspects of affective illness, as discussed in Section 15 . Such a strategy would require the measurement of behavioral, physiological (e.g., neuroendocrine and polysomnographic parameters), and biochemical variables before, during, and after drug treatment. Concepts and methods essential to using these agents in studying (modeling) the pathophysiology of affective disorders are reviewed elsewhere ${ }^{47}$.

\section{DRUG ABUSE DATA}

Euphorigenic properties ${ }^{215.238,252,253}$ render antimuscarinic agents substances of abuse. Other euphoriants including marijuana, alcohol ${ }^{27.200 .239 .249}$, barbiturates $^{262-264,283}$, and opiates ${ }^{51,124,125,195,222}$, show a similar capacity to antagonize cholinergic systems. Marijuana, ethanol, and barbiturates are all inhibitors of acetylcholine release, whereas classic antimuscarinic agents, and tricyclic antidepressants directly block the postsynaptic muscarinic receptor. Either event can cause supersensitization of cholinergic networks.

Marijuana abuse has been implicated in the genesis of 'hypomanic-like' syndromes ${ }^{158,212}$. Cannabinoid-induced decreases in the release of acetylcholine could account, at least in part, for this phenomenon. Reduced cholinergic activity produces euphoria and hyperactivity, cardinal features of hypomania. Carmichael and Israel ${ }^{127}$, studying the propensity of ethanol to inhibit electrically stimulated retease of several neurotransmitters from rat cortical slices, found it to be a potent inhibitor of acetylcholine release; the $\mathrm{IC}_{50}$ of ethanol for the inhibition of acetylcholine release was only $34-35 \%$ that for monoamines. Acetylcholine, at a blood ethanol concentration marking moderate to severe intoxication, showed the greatest reduction in release of all neurotransmitters screened. Tabakoff et al. ${ }^{249}$ observed that 7 days of ethanol administration produced a $115-125 \%$ increase in specific $\left[{ }^{3} \mathrm{H}\right] \mathrm{QNB}$ binding in hippocampal and cortical homogenates derived from mice. Ethanol was undetectable in blood $8 \mathrm{~h}$ after its discontinuation but physical dependence was demonstrated by seizures during the first $24 \mathrm{~h}$ of abstinence. Smith ${ }^{239}$ gave ethanol, $7 \%$ by volume in water, to mice for 8 days. This regime produced severe dependence as evidenced by hyperactivity (e.g., whole body tremor) and convulsions upon routine handling. 
A cholinergically enriched synaptosomal fraction from brain demonstrated a $128 \%$ increase in specific radioantonist $\left(\left[{ }^{3} \mathrm{H}\right] \mathrm{QNB}\right)$ binding. Rabin et al. ${ }^{200}$ also found that ethanol, $7 \%$ by volume, increased the density of $\left[{ }^{3} \mathrm{H}\right] \mathrm{QNB}$ binding sites in hippocampus and cerebral cortex.

Treatment with an agent diminishing the quantal release of acetylcholine induces supersensitivity of cholinergic systems. Wahlstrom ${ }^{264}$ reported, using choline-induced seizures as an index, that chronic barbital treatment induced cholinergic system supersensitivity. Wahlstrom and Nordberg ${ }^{263}$ observed that velocity of choline uptake is increased 12 days after the discontinuation of barbital in rats. This parameter is related to the rate of acetylcholine synthesis and utilization. Nordberg and Wahlstrom ${ }^{182}$ found that treatment of rats with atropine early in the postbarbital withdrawal phase significantly decreased the morbidity of barbiturate withdrawal. When the rats were sacrificed 81-83 days after barbital discontinuation, a reduction in brain weight was found in those animals receiving saline instead of atropine. The concentration of endogenous acetylcholine was decreased in barbital-treated rats. This variable bore a relationship to reduction in brain weight. Wahlstrom and Ekwall ${ }^{262}$ showed that an exaggerated hypothermic response to pilocarpine occurs concomitant with the development of tolerance to a barbiturate. Nordberg and Sundwall ${ }^{183}$ found that a single dose of pentobarbital decreased acetylcholine turnover. Domino and Wilson ${ }^{51}$ showed that pentobarbital inhibited the utilization of acetylcholine. Anesthetizing doses completely blocked the hemicolinum3 induced depletion of brain acetylcholine in rats, implying a blockade of acetylcholine release. Schuberth et al. ${ }^{226}$ corroborated this finding. All of these considerations suggest that barbiturates acutely decrease the activity of cholinergic systems, presumably by diminishing presynaptic release of acetylcholine. This diminution would promote supersensitivity of cholinergic networks and provide a pathophysiological basis for development of cholinergic overdrive associated with barbiturate withdrawal.

Signs and symptoms of opiate withdrawal include coryza, sialorrhea, nausea, vomiting, anorexia, diarrhea, myalgias, sleeplessness, anxiety, agitation, irritability, headaches, dizziness, tachycardia, and hypertension. Anticholinesterases and tricyclic antide- pressant withdrawal produce similar clinical features $^{39,43}$. Withdrawal of these drugs may induce states of cholinergic overdrive, though this is not to suggest that these manipulations lack other consequences essential to their effects. There is in fact evidence that opiate withdrawal involves a cholinergic component. Several investigators have reported that narcotic agonists block release of acetylcholine from corte $^{51}$ and guinea pig ilium ${ }^{125,195,222}$. The meaning of this finding is disputed ${ }^{124,125,195}$ because of failure to demonstrate increased brain acetylcholine concentration during the withdrawal phase or elevation of the baseline concentration of acetylcholine at critical central loci after opiate treatment. This criticism, however, is based on the faulty assumption that treatment with pharmacological agents diminishing the quantal release of acetylcholine must produce increased release of acetylcholine during drug withdrawal in order to cause a withdrawal syndrome. Cholinergic, monoaminergic, peptidergic, and GABAergic systems interact; perturbations of cholinergic networks induce changes in other neurotransmitter systems and vice-versa. These interactions must be taken into account when studying normal and abnormal cholinergic mechanisms. D-Amphetamine enhances utilization of acetylcholine in brain ${ }^{163}$, which might lead to the supposition that $\mathrm{D}$-amphetamine causes dysphoria, not euphoria. When the mechanisms underlying D-amphetamine's actions are understood, however, there remains no inconsistency with a theory positioning cholinergic system overdrive as a hallmark of dysphoric states, since amphetamine can be properly regarded as an agent that produces both release of acetylcholine and euphoria.

Dilsaver and Greden ${ }^{48}$ developed the idea of 'cholinergic monoaminergic interaction' in the pathophysiology of affective illness and presented it as a theoretical principle that might explain the phenomenology, LHPA axis dysfunction, polysomnographic abnormalities, and rapid changes in clinical state observed in rapidly cycling bipolar patients. For the purpose of illustration, consider the 'central pain' of melancholia ${ }^{38}$, a phase referring to a vague, inexplicable, and overpowering agony characterizing the experience of the melancholic. Its severity may be assumed to be a function of two complex variables, each variable containing within itself multiple additional terms; these subvariables correspond to the 
myriad of factors that combine to determine the ultimate status of cholinergic and monoaminergic systems. The cholinergic and monoaminergic systems, however, stand in a dynamic relationship marked by perpetual interaction, interregulation, and autoregulation. Thus, increased release of acetylcholine may be associated with euphoria if the status of monoaminergic systems relative to cholinergic systems meets certain contingencies. Similarly, opiate-induced supersensitivity of muscarinic cholinergic systems could precipitate cholinergic overdrive upon drug discontinuation without withdrawals increasing the release of acetylcholine. The amount of neurotransmitter release is but one of many subvariables defining the one complex variable that describes the status of cholinergic systems.

Amphetamine activates the reticular activating system (RAS) ${ }^{164}$. Electrical or pharmacological stimulation of this network causes release of acetylcholine at the cortex ${ }^{132,167,248}$, an event essential to the induction of EEG desynchrony, the classic EEG correlate of alertness. The RAS also activates limbic structures mediating behavioral arousal ${ }^{48}-$ that is, stimulation of the RAS has indirect effects upon limbic nuclei which are dependent on anatomic continuity between these sites. But D-amphetamine also acts directly on the mesolimbic system and thereby excites the ascending activating system. Similarly, it indirectly mobilizes limbic monoaminergic systems which regulate mood and psychomotor function, but it also activates these nuclei directly.

Observations that opiate withdrawal produces cholinergic overdrive-like symptoms though opiate treatment does not increase brain acetylcholine concentration or release of acetylcholine can be explained using the same line of reasoning. The assumption that there should be a measurable increase in brain acetylcholine concentration in the context of opiate treatment disregards the principle of 'autoregulation' of acetylcholine synthesis. The synthesis of acetylcholine is sensitive to the intraneuronal concentration of acetylcholine. Acute and chronic opiate administration can have opposite effects on acetylcholine synthesis and acetylcholine concentration. Protracted drug treatment may not produce rises in brain acetylcholine concentration because of the operation of compensatory mechanisms. After an acute or initial phase, the neuron may respond to chronic decreased release of or need for acetylcholine by diminishing its synthesis. This explanation accords with observations of the ways in which cholinergic neurons regulate the intraneuronal concentration of acetylcholine.

A solution to the 'problem' posed by the finding there is no increase in the release of acetylcholine during the opiate withdrawal phase requires precise definitions of 'up-regulation' and 'supersensitivity'. The term 'up-regulation' means that there is a statistically significant increase in the density of specific ligand binding sites $\left(\mathrm{B}_{\mathrm{max}}\right)$ on a given type of receptor. Everything else being equal, up-regulation is associated with supersensitivity to an agonist. In some circumstances, however, up-regulation may occur without development of supersensitivity. 'Supersensitivity' refers to enhanced behavioral, physiological or biochemical responses to endogenous or exogenous agonists. Supersensitivity can be due to several mechanisms that can be categorized according to location of neuronal modifications ${ }^{46}$. First, intra-neuronal events can potentiate effects of agonists on neurons with normal receptor density. For example, phosphodiesterase inhibitors act by inhibiting the destruction of cyclic-AMP in adrenergic neurons. Second, enhanced release of an endogenous agonist can produce supersensitivity. Increased availability of a neurotransmitter in a releasable pool provides the basis for exaggerated release of catecholamine upon amphetamine challenge. Amphetamine-induced hypertensive crisis in patients being treated with monoamine oxidase inhibitors is an example of this phenomenon. Third, supersensitivity can result from increased effectiveness of agonist-receptor coupling consequent to receptor modification or to intramembrane or intra-neuronal changes that amplify the effects of agonist-receptor binding. Enhanced effectiveness of agonist-receptor coupling in promoting ionic flux through ion channels is illustrative. The benzodiazepine receptor complex is a good example. This complex includes a site for binding $\gamma$ aminobutyric acid and a chloride channel ${ }^{6}$, and the effectiveness of an agonist binding to the benzodiazepine receptor is dependent on the functional status of the other elements forming the complex.

Let us consider the nature of narcotic withdrawal states in light of these points. Suppose that opiate treatment shifts the dose-response curve for devel- 
opment of some symptoms by acetylcholine to the left. Such a shift would occur if opiate treatment caused supersensitivity of cholinergic systems. Opiate-induced cholinergic system supersensitivity could provide a pathophysiological basis for development of cholinergic overdrive when opiates are withdrawn; a withdrawal-associated increase in acetylcholine release would not be required.

In conclusion, opiates may modify cholinergic systems, monoaminergic mechanisms, or cholinergicmonoaminergic interaction, and the pathophysiology of narcotic withdrawal states could be directly related to these changes. The role of cholinergic mechanisms in mediating the effects of opiates and their withdrawal warrants further study. The relationships of abusable substances to cholinergic systems involved in the regulation of mood, affect, psychomotor function, and hedonia could also be heuristically important ${ }^{48}$. Such substances may be useful in the study of mechanisms related to subjective elements and objectively measured correlates of the affective disorders.

\section{TENTATIVE EVIDENCE FOR THE CHOLINERGIC HYPOTHESIS: BRAIN MUSCARINIC RECEPTOR AL- TERATIONS IN SUICIDE VICTIMS}

Meyerson and associates ${ }^{173}$ measured the $B_{\max }$ of ligand binding to the muscarinic and $\beta$-adrenergic receptors and the density of imipramine binding sites in brain tissue obtained from 8 victims of violent suicide and control subjects dying suddenly in automobile mishaps or violent homicides. They found increases of $47 \%$ and $35 \%$ in $\left[{ }^{3} \mathrm{H}\right] \mathrm{QNB}$ and $\left[{ }^{3} \mathrm{H}\right]$ imipramine binding sites, respectively, in the suicide group as compared to the control group. The density of $\left[{ }^{3} \mathrm{H}\right] \mathrm{di}-$ hydroalprenlol binding sites, an index of $\beta$-adrenergic receptor density, did not distinguish groups. Agonists and antagonists, such as tricyclic antidepressants, can interfere with binding experiments. The investigators therefore measured imipramine, desipramine, and amitriptyline levels in corticol tissue, using an assay sensitive to $50 \mathrm{pg} / \mathrm{mg}$ of tissue, in an effort to determine whether recent tricyclic treatment might have been a confounding variable. Antidepressants were not detectable. This finding does not, however, exclude the possibility of antidepressant effects on the experimental variables.
Post-mortem studies have inherent limitations. These limitations include, but are not restricted to, difficulties in gathering accurate psychiatric and medical histories as well as lack of information on substance abuse and use of centrally active pharmacologic agents used in treating primary neurological, medical and psychiatric diseases. These confounding variables can complicate data interpretation and contribute to false positive and negative results. Moreover, sample bias may interfere with post-mortem studies, especially those based on small samples. Unidentified sources of sample bias would occur if suicide victims contained either an insufficiency or excess of individuals with affective disorders. Such biases could contribute to chance rejection of a true experimental hypothesis (type I error) or to erroneous acceptance of the null hypothesis (type II error).

Power of statistical tests may limit the meaning of a negative suicide study. The power of a test is the probability that it will detect, assuming random sampling and absence of sample bias, a difference between groups or categories when in actuality there is a difference. Low statistical power raises the probability of type II errors. Everything else being equal, the power of tests increases with sample size. A positive report based on the study of small samples can be suggestive, but a negative report speaks only weakly against the null hypothesis. The positive result reported by Myerson et al. ${ }^{173}$, based on a sample of 8 , may be important. This conclusion, however, would assume that the two groups (suicide and homicide/accident victims) were quasi random samples of the populations the investigators intended to study and that significant sources of variance that do not contribute to real group differences did not affect the groups differentially.

A negative report by Kaufmann et al. ${ }^{141}$ also presents the problem of small sample size. Low statistical power may not be the major issue in this study, however. First, $B_{\max }$ of $\left[{ }^{3} \mathrm{H}\right] \mathrm{QNB}$ binding in fmol of ligand/mg protein was $185 \pm 80$ vs $170 \pm 66$ in the frontal cortices of suicide and control groups, respectively. With sufficient sample size, this difference might reach statistical significance. Would it to be of practical significance, however? Criteria for establishing the relevance of an $8 \%$ difference would have to be established, in consultation with the neurochemist. However, with sufficient sample size, the most note- 
worthy finding to emerge could be a lower $\mathrm{B}_{\max }$ for $\left[{ }^{3} \mathrm{H}\right] \mathrm{ONB}$ binding in the hypothalamus of suicide victims compared to controls, $122 \pm 46$ vs $187 \pm 98 \mathrm{fmol}$ of ligand/mg protein, respectively. This result provides, as the investigators state, a trend in a sample of 10 , but it is opposite to the direction predicted. Such a small sample allows bias too easily to obscure or create differences between experimental and control groups. Perhaps sample size contributed to this unexpected finding.

A major difficulty in suicide-receptor ligand binding studies is the problem of justifiable inference. Does documentation of muscarinic receptor up-regulation in a sample of suicide victims justify the conclusion that affective illness is associated with muscarinic receptor up-regulation? Kaufmann and associates $^{141}$ acknowledged that they measured muscarinic receptor ligand binding sites not in affective disorder patients but rather in suicide victims. Barraclough $^{9}$ reported that only $53 \%$ and $11 \%$ in a sample of 106 suicide victims met diagnostic criteria for major depression and bipolar disorder, respectively. If the average frequency of affective disorder in the samples studied by Myerson et al. and Kaufmann et al. is 0.53 , these samples would include 4.24 and 5.3 affective disorder subjects. Moreover, the small sample sizes of 8 and 10 increase the probability of both upward and downward deviation of the mean sample frequency of affective illness from the hypothetical population mean of 0.53 .

Unidentified sources of variance threaten to diminish the lucidity of any body of data, but they are more likely to be limiting when one is working with small samples or dealing with certain biological, behavioral, and sociological variables (e.g., suicide, effects of genetics on muscarinic receptor binding parameters, influences of past and present drug abuse and pharmacotherapy on outcome, marital status, etc.). One cannot partial out effects of all confounding variables, but steps can be taken to minimize their impact. Some confounding variables can be measured and sample size increased in order to reduce the chance that the data will be unduly influenced by random occurrences.

Measurement of muscarinic receptor binding parameters in larger samples of suicide victims and control groups could be valuable. The largest suicide study of this type to date involved 22 subjects and yielded 'negative' results ${ }^{245}$. A prospective study could be carried out if one had a very large sample of affective disorder patients and control subjects, possibly non-affectively ill psychiatric patients. Pokony ${ }^{198}$ followed a sample of 4800 patients consecutively admitted to the in-patient psychiatric service of a Veterans Administration Hospital. During a 5-year follow-up period, there were 67 suicides - a rate of 2.79 deaths per 1000 subjects due to suicide annually, which is 12 times the expected frequency. There is also a relatively high rate of violent death due to accidents and homicide in the younger segment of a Veterans Administration Hospital population, providing a logical control group. Thus, a prospective study of muscarinic receptor binding parameters in victims of suicide with affective and non-affective disorders is 'doable'.

\section{TENTATIVE EVIDENCE FOR THE CHOLINERGIC HYPOTHESIS: NEUROCHEMICAL EFFECTS OF SLEEP DEPRIVATION}

Total and partial REM sleep deprivation produce decreases in depressive symptomatology in some endogenously depressed subjects $80,143,145,159,197,213,214$, 260,261 . There may be an association between depressive subtype, REM sleep variables, and response to sleep deprivation. Subjects responding to sleep deprivation are more apt than non-responders to have neurovegetative signs and symptoms and rebound increases in REM pressure following REM deprivation $^{143-145,159,197,214,224,260,261}$. Nasrallah and Coryel ${ }^{177}$ and King et al. ${ }^{145}$ reported that non-suppression to dexamethasone challenge predicted positive responses to sleep deprivation.

Bowers et al. ${ }^{16}$ studied effects of REM sleep deprivation on acetylcholine levels in the telencephalon (cortex, hippocampus and caudate), diencephalon (thalamus and hypothalamus), and the brainstem posterior to the colliculi and anterior to the obex in rats. The animals showed a significant drop in brain acetylcholine concentration in the telencephalon after $96 \mathrm{~h}$ of REM sleep deprivation. These changes do not appear to be due to a non-specific effect of stress; restraint and activity whecl stress did not produce these effects.

Trusihiya et al. ${ }^{257}$ studied effects of total, partial, and REM sleep deprivation on monoamine and ace- 
tylcholine content in rat brain. Changes in acetylcholine, serotonin, and norepinephrine content were measurable after 10 and $24 \mathrm{~h}$ of total sleep deprivation. Twenty-four hours of partial sleep deprivation was associated with an increase in telencephalic acetylcholine concentration $(P<0.02$ two-tailed $t$-test $)$, and a significant decrease in serotonin $(P<0.01$, two-tailed $t$-test) and a trend towards reduction in norepinephrine levels $(P>0.05<P<0.10)$, respectively in the diencephalon. Thirty minutes of sleep following $24 \mathrm{~h}$ of sleep deprivation increased serotonin and norepinephrine levels, thus eliminating differences between experiment and control rats. Ninety-six hours of REM sleep deprivation were associated with a reduction in telencephalic acetylcholine concentration of $11.8 \%(P<0.05)$, compared to 8 control animals. Total sleep deprivation for $24 \mathrm{~h}$ caused a $22.1 \%$ decrease in telencephalic acetylcholine concentration in experimental compared to control animals. Ninety-six hours of total REM sleep deprivation were also associated with significant decreases in diencephalic and mesencephalic norepinephrine concentrations. In contrast, serotonin concentrations did not change in any region examined.

Sagales and Domino ${ }^{221}$ measured steady-state whole brain acetylcholine concentration in animals deprived of REM sleep for 24,48 and $96 \mathrm{~h}$ and 6 days. They found no changes. Their methodology, however, differed from that employed by Trusihiya et al. ${ }^{257}$ and Bowers and associates ${ }^{16}$, in that the latter investigators isolated brain regions having potentially different sensitivities to REM sleep deprivation. A marked change in acetylcholine concentration consequent to the various sleep deprivation maneuvers could occur at given sites without detectable changes in whole brain.

Total, partial, and REM sleep deprivation might also produce important changes in central cholinergic systems not detectable by measuring regional alterations in acetylcholine concentration. In vivo muscarinic receptor binding studies and measurement of physiological endpoints promise to be of value in determining the effects of various forms of sleep deprivation. Binding parameters can be measured in vivo in sleep-deprived animals using $\left[{ }^{3} \mathrm{H}\right]$ scopolamine as the receptor ligand. After in vivo administration of the radioligand, animals are sacrificed, the brain dissected, and the regional density of ligand binding sites determined using an autoradiographic technique. Tracer kinetic modeling conjoined with an autoradiographic technique allows measurement of receptor binding site density in 'infinite' brain regions simultaneously ${ }^{69-72}$. This methodology is more powerful and less time-consuming than alternatives for determining muscarinic receptor binding parameters in vivo.

Systemically administered anticholinesterases and cholinomimetics induce hypothermia in rats and mice $5,74,79,146,162,163,172,175,176,192$. The magnitude of this response before and after sleep deprivation may provide a means of monitoring change in the function of a cholinergic mechanism - that is, cholinomimetic-induced hypothermia can provide an index of the sensitivity of cholinergic systems ${ }^{42}$. This variable may also allow study of the effects of different types of sleep deprivation on cholinergic mechanisms. Other physiological variables are also useful in physiological and receptor binding studies. Moreover, each animal can serve as its own control. This design allows use of paired parametric statistical models which provide greater power than otherwise attainable. Cholinergic activating agents produce cholinergic system down-regulation and subsensitivity and modify mechanisms regulating the release of acetylcholine $\mathrm{e}^{20,37,55,56,165,225,231,251,269,270}$. It is therefore essential that sufficient time elapses between individual cholinergic challenges to avoid carry-over effects, i.e. lasting effects produced by the previous pharmacologic challenges. For example, administration of an anticholinesterase to ascertain the baseline hypothermic response to cholinergic overdrive could interfere with the effects of the sleep deprivation and subsequent cholinergic challenges. These design problems, however, can generally be overcome.

The neurophysiology of sleep, sleep pathophysiology in affective disease, and the biology of sleep deprivation may soon be amenable to study using positron emission tomographic (PET) strategies. Appropriate muscarinic receptor radioligands are needed. In the interim, basic research involving animals is important.

In summary, total, partial, and REM sleep deprivation are effective treatments for some melancholics. Preliminary studies suggest they alter telencephalic acetylcholine concentrations. Acetylcholine concentration is a gross measure, and it does not indicate 
the functional status of cholinergic systems. Measurement of muscarinic receptor binding parameters in vivo and of physiological endpoints should yield data more accurately mirroring the effects of sleep deprivation procedures on central cholinergic systems.

\section{SUMMARY}

Several lines of evidence implicate dysfunction of cholinergic systems in the pathophysiology of affective disorders. They are best evaluated not only with reference to their factual content but also with regard for their potential for making future contributions to the study of the pathophysiology of affective illness and their conceptual significance. For the purpose of discussion, however, the evidence for the cholinergic hypothesis can be categorized according to the strength of factual support they provide. The capacity of anticholinesterases and cholinomimetics to produce behavioral features of the major affective syndromes and alter neuroendocrine and polysomnographic variables in a direction resembling the endogenous subtype provide the strongest evidence for a cholinergic link in the pathophysiology of affective illness. Findings that affective probands and their affectively ill relatives demonstrate supersensitivity to cholinergic challenge relative to control subjects (including non-ill relatives) also provide strong evidence for the hypothesis. Cholinergic system supersensitivity thus appears to be a heritable trait in subjects with affective illness.

Observations that antimuscarinic agents have antidepressant properties are noteworthy but need further evaluation. Cholinergic system supersensitivity may be an etiologic factor in affective disease, even though anticholinergics are of minimal utility as thymolytics. First, tolerance develops to these agents quite quickly. Secondly, cholinergic system supersensitivity is probably just one of many causal factors. Antidepressants like amitriptyline and imipramine are not merely anticholinergic drugs. Sorscher and Dilsaver ${ }^{242}$ have emphasized that the neuropharmacological effects of drugs are often not revealed by reductionistic accounts of their influences on a given neurotransmitter system studied in isolation. Interaction and interregulation of neurotransmitter systems is basic to normal neural function. This is certainly true of the tricyclics, all of which act on several systems simultaneously. Interaction may create a type of emergence. Thus, while more rigorously controlled clinical trials of treatment with antimuscarinics are indicated, the failure of these trials would not seriously impugn a cholinergic hypothesis.

Defects of hedonic capacity in the affective disorders and roles of cholinergic mechanisms in regulation of drive reduction behavior in animals suggest the importance of basic research in this area. The cholinergic and various monoamine hypotheses coalesce to yield accounts of greater explanatory power. Previous observations of cholinergic mechanisms in the regulation of hedonia are consistent with the hypothesis that an endogenously arising cholinergic overdrive state can produce anhedonia, but ongoing research is required before this becomes clinically pertinent (i.e., suggests experiments involving human subjects testing whether the cholinergic hypothesis extends to disturbances of hedonic capacity in depression).

Withdrawal of antimuscarinic drugs produces many of the characteristic of a depressive syndrome. These symptoms are aborted by centrally active antimuscarinic agents. These points argue for a type of spontaneously occurring cholinergic overdrive in certain types of depressive illness. Other drugs of abuse block the effects of acetylcholine presynaptically - i.e. directly decrease its release - act on monoaminergic systems, or do both simultaneously. Presumably, organisms seek what is the best for them, and the abuse of substances carries short-term benefits. Substance abuse provides a means for the self-regulation of mood, affect, and hedonia. Properties of abusable substances may be linked to effects upon cholinergic networks. The basic pharmacology of abusable drugs accords with the possibility that disturbances of mood, affect, and hedonic capacity involve dysfunction of cholinergic systems.

Postmortem studies have thus far involved insufficient numbers of subjects and have not adequately addressed methodological problems. Thus, appropriate tests of the hypothesis that victims of suicide have up-regulation of central muscarinic receptors remain to be conducted. Future studies will have to establish whether subjects really suffered from affective disorders. Such studics may have to be done prospectively. Partial and total sleep deprivation, useful 
treatments of depression, and inducers of hypomania and mania influence cholinergic variables but whether their cholinotropic properties relate to their efficacy is not yet known.

\section{FUTURE DIRECTIONS}

15.1. Future directions for studying cholinergic mechanisms involved in the pathophysiology of affective disorders

The capacity to produce defects in cholinergic systems mimicking those that occur spontaneously in affective disorder subjects would create many new experimental possibilities. Phenomenological, physiological, biochemical, and receptor binding measures are classes of dependent variables that are now useful in the study of affective disorders. Abnormalities of these variables can result from up-regulation and supersensitivity of cholinergic systems and disturbances of cholinergic-monoaminergic interaction. These deviations are safely and inexpensively produced by pharmacologic induction of up-regulation and supersensitivity of muscarinic cholinergic networks in both man and animals, presenting possibilities for using antimuscarinic agents in affective disorder investigations.

Hypotheses formulated by considering clinical data can be tested by applying pharmacological perturbation techniques in animals. A pathophysiologic role for supersensitivity of cholinergic systems in affective disease can be verified in humans by comparing cholinomimetic-induced changes in variables in affectively ill patients and in normal subjects before, during, and after chronic muscarinic receptor blockade. Dependent variables partially regulated by cholinergic systems include mood and affect, psychomotor function ${ }^{87-89}$, hedonic capacity (behavioral variables), body temperature, pupillary dynamics ${ }^{40}$, 47,228,229, REM latency and density, percent of REM during the first half of the nocturnal recording, sleep efficiency, DST status, absolute post-dexamethasone cortisol from a $\beta$-endorphin, ACTH concentrations, the distribution of regional EEG activity or power-spectral analysis ${ }^{253}$ (physiological variables), and rates of cyclic GMP generation ${ }^{57,133,134,240}$ or phospholipid turnover (biochemical variables) $)^{52,63-65}$.
15.2. Future directions: Use of normal subjects in modeling cholinergic abnormalities of depressive disorders

A conceptual framework for use of pharmacologic perturbation or modeling strategies has been presented elsewhere ${ }^{47}$. Effects of antimuscarinics can be measured in normal subjects using a design allowing them to serve as their own controls. These subjects could be compared to affective disorder subjects at any point of interest. Adverse effects of muscarinic receptor blockade should not be so severe as to prohibit such studies; doses of centrally active anticholinergic agents sufficient to produce the desired physiological and psychic effects have been administered to humans without ontoward effects ${ }^{1,14,18,24,33,59}$, $86,123,126,131,140,190,199,215,238,252,253,256,267,268$

Bringing together the interests and expertise of basic and clinical scientists by using these drugs to manipulate neurotransmitter systems on several levels, molecular to organismic, may prove particularly fruitful. For instance, withdrawal of tricyclics was found in the clinic to produce evidence of mesolimbic, mesocortical and nigrostriatal cholinergic overdrive and LHPA dysregulation. In subsequent laboratory studies, we observed treatment with amitriptyline ( 10 or 15 or $20 \mathrm{mg} / \mathrm{kg}$ i.p. twice daily) for 7 or more days markedly shifted the dose-response curve for induction of hypothermia by oxotremorine in Sprague-Dawley rats. That is, amitriptyline, supersensitized a cholinergic system as evidenced by change in the magnitude of the hypothermia produced by challenge with oxotremorine, 0.10 and 0.25 or $1.0 \mathrm{mg} / \mathrm{kg}$, before and after treatment $(P<0.05$, ANOVA with repeated measures $)^{41}$. The strategy of proceeding from man (clinical observations) to the intact animal (physiology) was quite useful.

15.3. Future directions: Defining the limits and scope of cholinergic abnormalities in the pathophysiology of affective disorders

There is strong support for the hypothesis that cholinergic mechanisms are operative in the pathophysiology of depressive disorders. Determining the limit and scope of their contribution to the phenomena of depressive disorders, however, is of critical imporance. It is all too easy to fall into the trap of considering cholinergic activity in isolation. If the nature of cholinergic systems is to be properly understood, in- 
teraction with other neurotransmitter systems (e.g., adrenergic, dopaminergic, serotonergic, GABAergic, peptidergic) must be carefully considered and clarified. The question we should be asking is, "What aspects of the phenomenological, neuroendocrinological, polysomnographic, diurnal, and autonomic abnormalities of affective disorders are related to the pathology of muscarinic cholinergic systems, and what aspects are due to abnormal interaction of cholinergic and other systems?"

We must first adopt criteria by which to determine whether a cholinergic component is involved at all. To begin with, we must establish a clear relationship between dependent variables (mood, affect, neuroendocrine status, pupillometric measures, etc.) and naturally or pharmacology-induced cholinergic overdrive. Secondly, we must identify cholinergic pathways or the anatomic substrata of deranged cholinergic mechanisms involved in producing those relationships between dependent variables and cholinergic overdrive. Studies of sleep disturbance are exemplary in this respect. Hobson and McCarley ${ }^{101-105.169,170}$ (cf. Section 5) have posited a dynamic interaction between a cholinergic network confined to the FTG (a pontine structure) and an adrenergic network, the locus coeruleus. Activation of the FTG tends to produce increased REM density and REM latency, features of melancholia. Thus, the challenge of verifying the relationship between sleep variables and cholinergic overdrive and of identifying the specific cholinergic pathways involved has helped to extend the frontiers of our knowledge.

\subsection{Future directions: Defining the loci of choliner-} gic abnormalities involved in the pathophysiology of affective disorders

Future study into the etiology of affective disorders may profit from a broadened conceptualization of the nature of the underlying cholinergic defect. Current evidence pointing to supersensitivity of cholinergic systems does not indicate the site of dysregulation. Typically, the locus of abnormality is implied to be the postsynaptic muscarinic receptor. Cholinergic phenomena observed in affective disorder patients, however, could also result from abnormal presynaptic mechanisms, membrane pathophysiology or derangement of intra-cytosolic mechanisms intended to amplify the effectiveness of receptor-agonist cou- pling, or aberrant cholinergic-monoaminergic interaction. For example, presynaptic mechanisms regulate the release of acetylcholine. Defects of the presynaptic autoreceptor could promote excessive release of acetylcholine, leading to an endogenously arising cholinergic overdrive state. The possibility of pathophysiology at the level of the receptor, in the regulation of receptor density, in presynaptic control of acetylcholine release, in membrane dynamics, or in cascade mechanisms was recently addressed ${ }^{46}$. This type of dissection can help to promote clarity of thought in this area of research and to suggest alternative approaches to the topic of cholinergic system supersensitivity in the pathophysiology of affective illness.

\subsection{Further directions: Beyond the cholinergic hy- pothesis}

Cholinergic pathology is not likely to explain 'all the variance'. There are features of the depressed state or of the longitudinal course of affective disorders that may be best understood in terms of the interaction between cholinergic and monoaminergic systems or of other factors.

Efforts to deepen our understanding of any natural phenomenon demand hypotheses, and hypotheses are amenable to verification, at least in principle. Verification or validation can mean to establish as true or false', using accepted methodology, application of the canons of data analysis, and standards of interpretation prevailing in a field. In actuality, validation may mean that given hypotheses come to be recognized as being 'reasonable' or 'worthy' of acceptance. The value of hypotheses lies in their capacity to stimulate fruitful intellectual activity - i.e., to increase understanding of phenomena, generate important questions for scrutiny, and promote the amelioration of human suffering.

The pathophysiology of the affective disorders has been studied from many perspectives. Within biological circles, the two approaches that have enjoyed the greatest influence are the various 'monoaminergic' hypotheses ${ }^{21,22,32.223,258}$ and the chulinergic ${ }^{114}$ hypothesis. Both have served their purposes well; both have tremendous heuristic value. Nevertheless, if one insists that a hypothesis is verified or validated only if it provides a sufficient and adequate explanation for a phenomenon, then both are 'false'. Howev- 
er, application of such a rigid standard of truth to hypotheses tends to lead to their devaluation. It is difficult to integrate all of the available knowledge pertinent to the topic of this article but integration alone does justice to those who articulated and studied the various hypotheses we are discussing. Integration of knowledge regarding the inter- and intraregulation of cholinergic and monoaminergic (dopaminergic, adrenergic, serotonergic) systems provides new and powerful means of viewing and understanding old phenomena. It can create 'realities', by making us aware of possibilities that we would not otherwise appreciate $^{152}$. Integration can raise questions which would not ordinarily be asked and it can thus lead to answers which would not have otherwise been sought. Hence, it proceeds from an existing body of knowledge to new knowledge.

In my judgment, affective disorders research is in need of not only the integration of seemingly disparate perspectives (e.g., cholinergic, monoaminergic), but the development of comprehensive models fostering basic research pari passu with clinical studies. Such models would focus on the study of relevant phenomena based on the critical examination of multiple phenomenological, physiological, biochemical, and brain imaging variables in normal and ill human subjects and laboratory animals. Our task is one of synthesis rather than multiplication of hypotheses, of collaboration rather than fragmentation. The importance of the body of research described in this review lies not only in the contribution it has made toward promoting knowledge and ameliorating human pain, but also in the solid basis it provides for building the conceptually broader models needed for the future.

\section{REFERENCES}

1 Abood, L.G. and Meduna, L.J., Some effects of a new psychotogen in depressive states, J. Nerv. Ment. Dis., 127 (1958) 546-550.

2 Akil, H., Watson, S.J., Young, E., Lewis, M.E., Khachaturian, H. and Walker, J.M., Endogenous opioids: biology and function, Ann. Rev. Neurosci., 7 (1984) 223-255.

3 Andersonn, K., Fuxe, K. and Agnati, L.F., Effects of single injections of nicotine in the ascending dopamine pathways in the rat. Evidence for increases in dopamine turnover in neostriatal and mesolimbic dopamine neurons, Acta Psychiat. Scand., 112 (1982) 345-347.

\section{SUMMARY}

Evidence supporting a cholinergic hypothesis of depression is presented. First, cholinergic overdrive produces behavioral, neuroendocrine, and polysomnographic features of melancholia, and melancholics exhibit state-independent supersensitivity to cholinergic overdrive. Drugs inducing up-regulation and supersensitivity of cholinergic systems produce behavioral, polysomnographic, and neuroendocrine effects of melancholia when withdrawn. These observations also implicate cholinergic system supersensitivity as a factor in the pathophysiology of certain affective disorders. Cholinergic and monoaminergic mechanisms reciprocally regulate drive-reduction, and substances of abuse either activate monoaminergic networks or antagonize cholinergic systems. These points are consistent with the hypothesis that dynamic interaction between cholinergic and monoaminergic systems is involved in the regulation of mood and affect. Finally, antimuscarinic agents have antidepressant effects. Thus, the hypothesis that supersensitivity of cholinergic systems is involved in the pathophysiology of affective disorders is supported by several lines of evidence. This evidence is reviewed; directions for future research and promising methods of investigation are discussed.

\section{ACKNOWLEDGEMENTS}

Supported in part by a Physician Scientist Career Development Award, Grant no. SRC1K11 MH00553-01 (Muscarinic Receptor Abnormalities in Affective Illness), awarded by the National Institute of Mental Health.

4 Atkinson, J. and Landinsky, H., The quantitative study of the anticholinergic action of several tricyclic antidepressants on the rat isolated fundal strip, Br. J. Pharmacol., 45 (1972) 519-524.

5 Avery D.D., Intrahypothalamic adrenergic and cholinergic effects on temperature and ingestive behavior in the rat, Neuropharmacology, 10 (1971) 753-763.

6 Baestrop, C., Neurotransmitters and CNS disease: anxiety, Lancet, 2 (1982) 1030-1034.

7 Baldessarini, R.J., Drugs and the treatment of psychiatric disorders. In A.G. Gilman, L.S. Goodman and A. Gilman (Eds.), The Pharmacological Basis of Therapeutics, 6th edn. Macmillan, New York, 1980, p. 423. 
8 Barnes, C.D. and Meyers, F.H.. Eserine and amphetamine: interactive effects on sleeping time in mice, Science, 144 (1964) $1221-1222$.

9 Barraclough, B., Bunch, J., Nelson, B. and Sainsbury, P.A., A hundred cases of suicide: Clinical aspects, Brit. $J$. Psychiatr., 125 (1974) 355.

10 Beani, L. and Bianchi, C., Effect of amantadine on cerebral acetylcholine release and content on the guinea pig, Neuropharmacology, 12 (1968) 283-289.

11 Beigel, A. and Murphy, D.L., Assessing clinical characteristics of the manic state, Am. J. Psychiat., 128 (1971) 44-50.

12 Ben-Barak, Y. and Dudai, Y., Scopolamine induces an increase in muscarinic receptor level in rat hippocampus, Brain Res., 193 (1980) 309-313.

13 Blackwell, B., Stefopoulos, A., Enders, P., Kuzuma, R. and Adolphe, A., Anticholinergic activity of two tricyclic antidepressants, Am. J. Psychiatr, 135 (1978) 22-24.

14 Bolin, R.R., Psychiatric manifestations of artane toxicity, J. Nerv. Ment. Dis., 131 (1960) 256-259.

15 Bowers, M.B., Goodman, E. and Sim, V.M., Some behavioral changes in man following anticholinesterase administration, J. Nerv. Ment. Dis., 138 (1964) 383-389.

16 Bowers, M.B., Hartmann, E.L. and Freedman, D.Y., Sleep deprivation and brain acetylcholine, Science, 153 (1966) 1416-1417

17 Bradbury, M.W.B., Burden, J, Hillhouse, E.W. and Jones, M.T., Stimulation electrically and by acetylcholine of the rat hypothalamus in vitro, J. Physiol. (London), 239 (1974) R269-283.

18 Bradley, P.B. and Elkes, J., The effect of atropine, hyosine, physostigmine and neostigmine on the electrical activity of the brain of a conscious cat, J. Physiol. (London), $120(1963) 14-15$.

19 Briaud, B., Coke, P., Lutz-Bucher, B. and Mialhe, C. In vitro regulation of $\mathrm{ACTH}$ release from neurointermediate lobe of rat hypophysis. II. Effect of the neurotransmitter, Neuroendocrinology, 28 (1979) 377-385.

20 Briggs, C.A. and Cooper, J.R., Cholinergic modulation of the release of $\left[{ }^{3} \mathrm{H}\right]$ acetylcholine from synaptogomes of the mysenteric plexus, J. Neurochem., 38 (1982) 501-508.

21 Bunney, W.E. and Davis, J.M., Norepinephrine in depressive reactions, Arch. Gen. Psychiatr., 13 (1965) 483-494.

22 Bunney, W.E. and Garland, B.L., A second generation catecholamine hypothesis, Pharmacopsychiatrica, 15 (1982) $148-150$.

23 Bunney, W.E. and Hamburg, D.A., Methods for reliable longitudinal observation of behavior, Arch. Gen. Psychiatr., 9 (1963) 281-294.

24 Callaway, E. and Band, R.I., Some physiological effects of atropine, Arch. Neurol. Psychiatr., 79 (1958) 91-102.

25 Cariton, P.L., Augmentation of the behavioral effects of amphetamine by atropine, Pharmacologist, 2 (1960) 70.

26 Carlton, P.L., Cholinergic mechanisms in the control of behavior by the brain, Psychol. Rev., 70 (1967) 19-39.

27 Carmichael, F.J. and Israel, Y., Effects of ethanol on neurotransmitter release by rat brain cortical slices, $J$. Pharmacol., 193 (1975) 824-834.

28 Carney, M.W.P., Roth, M. and Garside, R.F., The diagnosis of depressive symptoms and the prediction of ECT response, Brit. J. Psychiatr., 111 (1965) 659-674.

29 Carroll, B.J., Feinberg, M., Greden, J.F. et al., A specific laboratory test for the diagnosis of melancholia, Arch.
Gen. Psychiatr., 38 (1981) 15-22

30 Carroll, B.J., Frazer, A., Schless, A. et al, Cholinergic reversal of manic symptoms, Lancet $_{r} 1$ (1973) 427

31 Carroll, B.J., Greden, J.F., Haskett, R. et al, Neurotransmitter studies of neuroendocrine pathology in de pression, Acta Psychiatr. Scand., 61, Suppl. 280 (1980) 183-199.

32 Copper, A., Biochemistry of affective disorders, Brit. $J$. Psychiatr., 113 (1967) 1237-1264.

33 Crawshaw, J.A. and Mullen, P.E., A study of Benzhexol abuse, Br. J. Psychiatr., 145 (1984) 300-303.

34 Davis, B.M., Brown, G.M., Miller, M. et al., Effects of cholinergic stimulation on pituitary hormone release, $P$ sychoneuroendocrinology, 7 (1982) 347-384.

35 Davis, B.M. and Davis, K.L., Cholinergic mechanisms and anterior pituitary secretion, Biol. Psychiatr., 15 (1981) $303-310$

36 Davis, K.L., Hollister, L.E., Overall, J. et al., Physostigmine in Mania, Arch. Gen. Psychiatr., 35 (1) (1978) $119-122$.

37 de Belleroche, J. and Gardner, 1.M., Cholinergic action in the nucleus accumbens: modulation of dopamine and acetylcholine release, Br. J. Pharmacol., 75 (1982) 359-365.

38 Diagnostic and Statistical Manual of Mental Disorders, 3rd edn., American Psychiatric Association, Washington, D.C. 1980

39 Dilsaver, S.C. and Greden, J.F., Antidepressant withdrawal phenomena, Biol. Psychiatr., 19 (1984) 237-256.

40 Dilsaver, S.C. and Greden, J.F., Antidepressant withdrawal syndromes: evidence for supersensitivity of cholinergic system, J. Clin. Psychopharmacol, 3 (1983) 330

41 Dilsaver, S.C., Snider, R.M. and Alessi, N.E., Amitriptyline produces cholinergic system supersensitivity, Biol. Psychiatr., submitted.

42 Dilsaver, S.C. and Greden, J.F., The effects of antidepressant withdrawal on the DST status of endogenously depressed patients, Psychiatr. Res., 14 (1985) 111-115.

43 Dilsaver, S.C., Kronfol, Z., Greden, J.F. and Sackellares, J.C., Antidepressant withdrawal syndromes: evidence supporting the cholinergic overdrive hypothesis, J. Clin. Psychopharmacol, 3(1983) 157-164.

44 Dilsaver, S.C., Leckrone, J.G. and Greden, J.F., Cholinergic syndrome from psychotropic withdrawal in a marijuana abuser, Psychosomatics, 25 (1984) 632-634.

45 Dilsaver, S.C.. Lithium's effect on muscarinic receptor binding parameters: a possible relationship to therapeutic efficacy, Biol. Psychiatr., 14 (1984) 1558.

46 Dilsaver, S.C., Pathophysiology of Cholinoceptor 'Supersensitivity in Affective Disorders, Biol. Psychiatr., 21 (1986) 813-824.

47 Dilsaver, S.C., Pharmacologic Induction of cholinergic system supersensitivity, J. Clin. Psychopharmacol, 6 (1986) 65-74

48 Dilsaver, S.C. and Greden, J.F., Activation on antidepressant withdrawal: a possible mechanism and its theoretical significance, Brain Res. Rev., (1984) 29-42.

49 Doerr, P. and Berger, M., Physostigmine-induced escape from dexamethasone in normal subjects, Biol. Psychiatr. $18(1983) 261-268$

50 Domino, E.F. and Olds, M.E.; Cholinergic inhibition of self-stimulation behavior, J. Pharmacol., 164 (1968) 202-211.

51 Domino, E.F. and Wilson, A.E., Effect of narcotic anal- 
gesic agonists and antagonists on rat brain acetylcholine, J. Pharmacol. Exp. Ther., 184 (1973) 18-32.

52 Downes, P.C., Inositol phospholipids and neurotransmitter-receptor signalling mechanisms, Trends Neurosci., 6 (1983) $313-316$

53 Duffy, F.H., Burchfield, J.L. and Lombroso, C.T., Brain electrical activity mapping (BEAM): a method for extending the clinical utility of EEG and evoked potential data, Ann. Neurol., 5 (1979) 309-332.

54 Dukes, M.N.G., Social drugs. In M.N.G. Dukes (Ed.), Meyler's Side Effects of Drugs, Excerpta Medica, Amsterdam, 1980, pp. 51-54.

55 Ehlert, F.J., Kukka, N. and Fairhurst, A.S., Altered $\left[{ }^{3} \mathrm{H}\right] q u i n u c l i d i n y l$ benzilate binding in the striatum of rats following chronic cholinesterase inhibition with diisopropylfluorophosphonate, Molec. Pharmacol., 17 (1980) 29-30.

56 Ehlert, F.J. et al., The nature of muscarinic binding. In L.L. Iversen, S.D. Iversen and S.H. Snyder (Eds.), Handbook of Psychopharmacology, Vol. 17, Plenum, New York, 1983.

57 El-Fakahany, E. and Richelson, E., Effect of some calcium antagonists on muscarinic-mediated cyclic GMP formation, J. Neurochem., 40 (1983) 705-710.

58 El-Yousef, M.K., Janowsky, D.S., Davis, J.M. et al., Induction of severe depression by physostigmine in marijuana intoxicated individuals, Brit. J. Addict., 68 (1973) 321-325.

59 English, D.C., Reintegration of affect and psychic emergence with ditran: a clinical report and intepretation of results, J. Neuropsychiatr., 3 (1962) 304-310.

60 Fawcett, J., Clark, D.C., Scheftner, W.A. and Gibbons, R.D., Assessing anhedonia in psychiatric patients, Arch. Gen. Psychiatr, 40 (1983) 79-84.

61 Feighner, I.P., Rohins, E., Guze, S.B. et al., Diagnostic criteria for use in psychiatric research, Arch. Gen. Psychiatr., 26 (1972) 57-63.

62 Feinberg, M., Gillin, J.C., Carroll, B.J. et al., EEG studies of sleep in the diagnosis of depression, Biol. Psychiatr., 17 (1982) 305-316.

63 Fischer, S.K., Klinger, P.D. and Agranoff, B.W., Muscarinic agonist binding and phospholipid turnover in brain, $J$. Biol. Chem., 258 (1982) 7358-7363.

64 Fisher, S.K., Van Rooijen, L.A.A. and Agranoff, B.W., Renewed interest in the polyphosphainositides, Trends Neurosci., 7 (1984) 53-56.

65 Fisher, S.K. and Agranoff, B.W., The biochemical basis and functional significance of enhanced phosphatidate and phosphainositide turnover. In J. Eichberg (Ed.), Phospholipids in Nervous Tissues, John Wiley and Sons, New York, 1985.

66 Foster, C., Parkes, J. and Cox, B., Effects of olfactory bulbectomy and peripherally induced anosmia on thermoregulation in the rat: susceptibility to antidepressant type changes, J. Pharm. Pharmacol., 32 (1980) 630-634.

67 Foster, F.G., Kupfer, D.J., Coble, P.C. and Mipartland, R.J., Rapid eye movement sleep density, Arch. Gen. Psychiat., 33 (1976) 1119-1123.

68 Friedhoff, A.J. and Alpert, J., A dopaminergic-cholinergic mechanism in the production of psychotic symptoms, Biol. Psychiatr., 6 (1973) 165-169.

69 Frey, K., The In Vivo Determination of Ligand Binding Within the Central Nervous System, University of Michigan, 1984.
70 Frey, K.A., Ehrenkaufer, S., Beaucage, S. and Agranoff, B.W., Quantitative in vivo receptor binding. I. Theory and application of the muscarinic cholinergic receptor, $J$. Neurosci., 5 (1985) 421-428.

71 Frey, K.A., Ehrenkaufer, R.L.L. and Agranoff, R., Quantitative in vivo receptor binding. II. Autoradiographic imaging of muscarinic cholinergic receptors, Neuroscience, 5 (1985) 2407-2414.

72 Frey, K.A., Hichwa, R.D., Ehrenbaufer, R.L.L. and Agranoff, R.W., Quantitative in vivo receptor binding. III. Tracer kinetic modeling of muscarinic cholinergic receptor binding, PNAS, 82 (1985) 6711-6715.

73 Friedman, M.J. and Jaffe, J., A central hypothermic response to pilocarpine in the mouse, J. Pharmacol. Exp. Ther., 167 (1969) 34-44.

74 Friedman, M.J., Jaffe, J.H. and Sharpless, S.K., Central nervous system supersensitivity to pilocarpine after withdrawal of chronically administered scopalamine, J. Pharmacol., 167 (1969) 45-55.

75 Galen, R.S., Application of the predictive value model in the analysis of test effectiveness, Clin. Lab. Med., 685 (1982) 99

76 Galen, R.S. and Gambino, S.R.C., Beyond Normality: The Predictive Value and Efficiency of Medical Diagnosis, John Wiley and Sons, New York, 1975.

77 Ganong, W.F., Neurotransmitters involved in ACTH secretion: catecholamines, NY Acad. Sci., 297 (1977) 509-517.

78 Ganong, W.F., Neurotransmitters in pituitary function: regulation of ACTH secretion, Fed. Proc., 39 (1980) 2923-2930.

79 Gazit, H., Silaman, I. and Dudai, Y., Administration of an organophosphate causes a decrease in muscarinic receptor levels in rat brain, Brain Res., 174 (1974) 354-356.

80 Gener, R.H., Post, R.M., Gillin, J.C. and Bunney, W.S., Biological and behavioral effects of one nights sleep deprivation in depressed patients and normals, $J$. Psychiat. Res., 15 (1979) 21-40.

81 George, R., Haslett, W.L. and Jenden, D.J., A cholinergic mechanism in the brainstem reticular formation: Induction of paradoxical sleep, Int. J. Neuropharmacol., 3 (1964) 541-552.

82 Gershon, S. and Shaw, F.H., Psychiatric sequelae of chronic exposure to organophosphorus insecticides, Lancet, 1 (1961) 1371-1374.

83 Gillin, J.C., Duncan, W., Pettigrew, K.D. et al., Successful separation of depressed normal and insomniac subjects by EEG sleep data, Arch. Gen. Psychiatr., 36 (1979) $85-90$.

84 Gillin, J.C., Sitaram, N., Mendelson, W.B. and Wyatt, R.J. Physostigmine alters onset but not duration of REM sleep in man, Psychopharmacology, 58 (1978) 111-114

85 Gillin, J.C., Sitaram, N. and Duncan, W.C., Muscarinic supersensitivity: a possible model for the sleep disturbance of primary depression?, Psychiatr. Res., 1 (1979) $17-22$.

86 Goldman, M.E. and Erickson, C.K., Effects of acute and chronic administration of antidepressant drugs in the central cholinergic nervous system: comparison with anticholinergic drugs, Neuropharmacology, $22 \quad$ (1983) $1222-1285$.

87 Greden, J.F., Alhala, A.A., Smokler, I.A., Gardner, R. and Carroll, B.J., Speech pause time: a marker of psychomotor retardation among endogenous depressives, Biol. 
Psychiatr., 16(1981) 851-859.

88 Greden, J.F. and Carroll, B.J., Psychomotor function and affective disorders, Am. J. Psychiatr, 138 (1981) 1441-1448.

89 Greden, J.F. and Carroll, B.J., Decrease in speech pause time with treatment of endogenous depression, Biol. Psychiatr., $15(1980) 575-587$.

90 Grob, D. Harvey, A.M., Langworthy, O.R. et al., The administration of disopropylfluorophosphate (DFP) to man, John's Hopkins Med. J., 81 (1947) 257-266.

91 Grossman, S.P., Direct adrenergic and cholinergic stimulation of hypothalamic mechanisms. Am. J. Physiol, 202 (1962) 872-882.

92 Guillemin, R., Vargo, T., Rossier, J,, Minick, S., Ling, N., Rivier, C., Vale, W. and Bloom, F., Beta-endorphin and adrenocorticotropin are secreted concomitantly by the pituitary gland, Science, 197 (1977) 1367-1369.

93 Guy, W., ECDEU Assessment Manual for Psychopharmacology, Government Printing Office, Washington D.C., 1976. DHEW Publication No. (ADM) 76-338.

94 Hamilton, M., A rating scale for depression, J. Neurol. Neurosurg. Psychiatr., 23 (1960) 56-62.

95 Hedge, C.A. and De Wied, D., Corticotropin and vasopressin secretion after hypothalamic implantation of atropine, Endocrinology, 88 (1971) 1257-1259.

96 Hedge, G.A. and Smellik, P.G., Corticotropin release: inhibition by intrahypothalamic implantation of atropine, Science, 159 (1968) 891-892.

97 Henderson, W.R. and Wilson, W.C., Intraventricular in jection of acetylchuline and eserine in man. Q. J. Exp. Physiol. Cogn. Med. Sci, 26 (1936) 83-95.

98 Hernandez-Peon, R., Clark-Ibarra, G., Morgane, P.J. and Timolaria, C., Limbic cholinergic pathways involved in sleep and emotional behavior. Exp. Neurol., 8 (1963) 93-114.

99 Hill, S.Y., Reyes, R.B. and Kupfer, D.J., Imipramine and REM sleep: cholinergic mediation in animals, Psy. chopharmacology, 69 (1980) 5-9.

100 Hillhouse, E. W. Burden, J. and Jones, M.T., The effects of various putative neurotransmitters on the release of corticotropin releasing hormone from the hypothalamus of the rat in vitro. I. The effect of acetylcholine and noradrenaline, Neuroendocrinology, 17(1975) 1-11.

101 Hobson, J.A., McCarley, R.W., Pivik, R.T. and Freedman, R., Selective firing by cat pontine brain stem neurons in desynchronized sleep, $J$. Neurophysiol, 38 (1974) 497-511.

102 Hobson, J.A., McCarley, R.W. and Wyzinski, P.W., Sleep cycle oscillation: reciprocal discharge by two brainstem neuronal groups, Science, 189 (1975) 55-58.

103 Hobson, J.A., The cellular basis of sleep cycle control. In E.D. Weitzman (Ed.), Advances in Sleep Research, Spectrum, New York, pp. 217-250.

104 Hobson, J.A., The reciprocal interaction model of sleep cycle control: discussion in the light of Giuseppe Moruzzi's concepts. In O. Pompeiano and N. Ajmone (Eds.), Brain Mechanisms and Perceptual Awareness, Raven, New York, 1981, pp. 379-404.

105 Hobson, J.A. and McCarley, R.W., Spontaneous discharge rates of rat cerebellar purkinje cells in sleep and waking, Electroenceph. Clin. Neurophysiol., 3 (1972) 457-469.

106 Holsboer, F., Liebl, R. and Hofschuster, E., Repeated dexamethasone suppression test during depressive illness,
J. Affect. Disord., $5(1982) 93$.

107 Hroshige, T., Kneko, F.M. and Honma, K., Assays and dynamics of corticotropin-release and factor activity in rat hypothalamus, Ann. NY Acad. Sci., 297 (1977) 436- 454.

108 Innes, I.R. and Nickerson, M. Atropine, scopolamine and related antimuscarinic drugs. In L.S. Goodman and A. Gilman (Eds.), The Pharmacological Basis of Therapeutics, edn . 5, Macmillan, New York, 1975, p. 520.

109 International Classification of Disease 8. Revision. WHO, publ. No. 8921, Geneva, 1974.

110 Jaffe, J.H. and Sharpless, S. K. Pharmacologic denervation supersensitivity in the central nervous system, Res. Publ. Assoc. Res. Nerv. Ment. Dis., 46 (1968) 226-241

$111 \mathrm{Jaffe}$, J.H., Drug addiction and drug abuse. In A.G. Gilman, L.S. Goodman and A. Gilman (Eds.), The Pharmacological Basis of Therapeutics, edn. 6. Macmillan, New York, 1980, pp. 556-557.

112 Janowsky, D.S., Abrams, Groom, G. and Judd, L., Antagonism of cholinergic inhibition by lithium. Presented at the 131st Annual Meeting of the American Psychiatric Association in Atlanta, GA, 1978. New Research Abstract NRIS.

113 Janowsky, D.S., Davis, J.M., El-Yousef, M.K. et al., Acetylcholine and depression. Psychosom. Med., 35 (1973) 568

114 Janowsky, D.S., El-Yousef, M.K., Davis, J.M. et al., A cholinergic adrenergic hypothesis of mania and depression, Lancet, 2 (1972) 632 635

115 Janowsky, D.S., El-Yousef, M.K., Davis, J.M. et al.. Cholinergic antagonism of methylphenidate-induced stereotyped behavior. Psychopharmacology, 27 (1972) $295-303$.

116 Janowsky, D.S., El-Yousef, M.K., Davis, J.M. et al., Parasympathetic suppression of manic symptoms by physostigmine, Arch. Gen. Psychiatr., 28 (1973) 542-547.

117 Janowsky, D.S., El-Yousef, M.K., Davis, J.M. and Sekerke, H.J., Antagonistic effects of physostigmine and methylphenidate in man. Am. J. Psychiatr., 130 (1973) $1370-1376$

118 Janowsky, D.S., Risch, S.C., Parker, D. et al., Increased vulnerability to cholinergic stimulation in affect disorder patients, Psychopharmacol. Bull., 16 (4) (1980) 29--31.

119 Janowsky, D.S., Risch. S.C.. Judd, L.L., Parker, D.C. Kalin, N.H. and Huey, L.Y., Behavioral effects of physostigmine in affective disorder patients. In P.J. Clayton and J.R. Bennett (Eds.). Treatment of Depression, Raven, New York. 1982.

120 Janowsky, D.S., Risch, S.C., Huey, L.Y., Judd, L. and Raush, J.L., Hypothalamic-pituitary-adrenal regulation: neurotransmitters and affective disorders, Peptides, 4 (1983) $775-784$

121 Janowsky, D.S., Risch, S.C., Huey, L.Y. et al., Effects of physostigmine on pulse, blood pressure and serum epinephrine levels, Am. J. Psychiatr., 142 (1985) 738-740.

122 Jasper, H.H. and Tessier, J., Acetylcholine liberation from cerebral cortex during paradoxical (REM) sleep. Science, 172 (1971) 601-602.

123 Jellinek, T., Mood elevating effects of trihexyphenidyl and biperiden in individuals taking antipsychotic medication, Dis. Nerv. Syst., 38 (1979) 353-355.

124 Jhamandas, K., Sutak, M. and Bell, S., Modifications of precipitated morphine withdrawal syndrome by drugs affecting cholinergic mechanisms, Eur. J. Pharmacol., 24 (1977) 296-305 
125 Jhamandas, K.A. and Dickinson, G., Modification of precipitated morphine and methadone abstinence in mice by acetylcholine antagonists, Nature (London), 245 (1973) 219-221.

126 Jimmerson, D.C., Nurnberger, J.I., Simmons, S. and Gershon, E.S., Anticholinergic treatment for depression, Presented at the 135th Annual Meeting of the American Psychiatric Association, Toronto, Canada, May 15-21, Syllabus, 1982, pp. 218-219.

127 Jones, M.T. and Hillhouse, E.W., Neurotransmitter regulation of corticotropin-releasing factor in vitro, $A n n . N Y$ Acad. Sci., 297 (1977) 536-559.

128 Jouvet, M., Cholinergic mechanisms and sleep. In P.G. Waser (Ed.), Cholinergic Mechanisms, Raven, New York, 1975, pp. 455-476.

129 Jouvet, M., Paradoxical sleep. A study of its nature and mechanisms. In K. Akert, C. Bally and J.P. Schade (Eds.), Sleep Mechanisms, Progress in Brain Research, Vol. 18, Elsevier, Amsterdam, 1965, pp. 20-57.

130 Kalin, N.H., Wieler, S.J, McKiney, W.T., Kraemer, G.W. and Shelton, S.E., Where is the 'lesion' in patients who fail to suppress plasma cortisol concentrations with dexamethasone?, Psychopharmacol. Bull., 18 (1982) 219-221.

131 Kaminer, Y., Munitz, H. and Wijsenbelc, H., Trihyzyphenidyl (artane) abuse: euphoriant and anxiolytic, Brit. J. Psychiatr, 140 (1982) 473-474.

132 Kanai, T. and Szerb, J.C., Mesencephalic reticular activating system and cortical acetylcholine output, Nature (London), 205 (1965) 80-82.

133 Kanba, S. and Richelson, E, Lithium affects muscarinic function. Presented at the 39th Annual Convention and Scientific Program of the Society of Biological Psychiatry, Los Angeles, CA, May 2-6, 1984.

$134 \mathrm{Kanba}, \mathrm{S}$. and Richelson, E., Antimuscarinic effects of lithium, New Engl. J. Med., 310 (1984) 989-990.

135 Kaplanski, J, and Smellik, P.G., Analysis of the inhibition of ACTH release by hypothalamic implants of atropine, Acta Endocrinol., 73 (1983) 651-659.

136 Karczmar, A.G., Central actions of acetylcholine, cholinomimetics, and related drugs. In A.M. Goldberg and I. Hanin (Eds.), Biology of Cholinergic Function, Raven, New York, 1976.

137 Karczmar, A.G., Central cholinergic pathways and their behavioral implications. In W.G. Clark and J. Giudice (Eds.), Principles of Psychopharmacology, Academic Press, New York, 1970, pp. 57-86.

138 Karczmar, A.G., Cholinergic influences on behavior. In P.G. Waser (Ed.), Cholinergic Mechanisms, Raven Press, New York, 1975, pp. 501-529.

139 Karczmar, A.G., Longo, V.G. and Sotti De Carolis, A., A pharmacological model of paradoxical sleep: the role of cholinergic and monoamine systems, Physiol. Behav., 5 (1976) 175-182.

140 Kasper, S., Moises, H.W. and Beckman, H., The anticholinergic biperidin in depressive disorders, Pharmacopsychiatry, 14 (1981) 195-198.

141 Kaufman, C.A., Gillin, J.C., Hill, B. et al., Muscarinic binding in suicide, Psychiat. Res., 12 (1984) 47-55.

142 Khazan, N., Bar, R. and Sulman, F.G., The effect of cholinergic drugs on paradoxical sleep in the rat, Int. J. Neuropharmacol, 6(1967) 279-282.

143 King, D., Pathological and therapeutic consequences of sleep loss: a review, Dis. Nerv. Syst., 39 (1977) 873-879.
$144 \mathrm{King}, \mathrm{D}$., Sleep deprivation therapy in depressive syndrome, Psychomatics, 21 (1980) 404-407.

$145 \mathrm{King}, \mathrm{D}$., The dexamethasone suppression test as a predictor of sleep deprivation antidepressant effect, Psychiatr. Res., 7 (1982) 93-99.

146 Kirkpatrick, W.E. and Lomax, P., Temperature changes following iontophoretic injection of acetylcholine into the ventral hypothalamus of the rat, Neuropharmacology, 9 (1970) 195-202.

147 Kneko, F.M., Neurotransmitters involved in ACTH secretion: catecholamines, Ann. NY Acad. Sci., 297 (1977) 509-517.

148 Krieger, D.T., Serotonin regulation of ACTH secretion, Ann. NY Acad. Sci., 297 (1977) 526-535.

149 Krieger, D.T. and Krieger, H.P., Circadian pattern of plasma 17-hydroxycorticosteroid: alteration by anticholinergic agents, Science, 155 (1967) 1421-1422.

150 Krieger, D.T. and Rizzo, F., Serotonin mediation of circadian periodicity of plasma 17-hydroxycorticosteroids, Am. J. Physiol., 217 (1969) 1703-1707.

151 Kuhar, M.J., Central cholinergic pathways, physiologica and pharmacologic aspects. In M.A. Lipton, A. DiMascio and K.F. Killam (Eds.), Psychopharmacology, A Generation of Progress, Raven Press, New York, 1978, pp. 200-201.

152 Kuhn, T.H., The Structure of Scientific Revolutions, 2nd edn., University of Chicago Press, Chicago, IL, 1960.

153 Kumbarachi, M.N. and Nastuk, W.L., Effects of $\Delta^{9}$-tetrahydrocannabinol on excitable membranes and neuromuscular transmission, Molec. Pharmacol, 17 (1980) 344-345.

154 Kupfer, D.J., EEG sleep correlates of depression in man. In 1. Hanin an E. Usdin (Eds.), Animal Models in Psychiatry and Neurology, Pergamon, New York, 1978, pp. 181-188.

155 Kupfer, D.J., Foster, G., Reich, L. et al., EEG sleep changes as predictors in depression, Am. J. Psychiatr., 133 (1976) 622-626.

156 Kupfer, D.J., Hanin, I., Spiker, D.G., Neil, J. and Coble, P., EEG sleep and tricyclic plasma levels in primary depression, Commun. Psychopharmacol., 3 (1979) 73-80.

157 Kupfer, D.J. and Foster, F.G., Interval between onset of sleep and rapid eye movement sleep as an indicator of depression, Lancet, 2 (1972) 684-686.

158 Lacoursiere, R.B. and Swatek, R., Adverse interaction between disulfiram and marijuana: a case report, $A m$. $J$. Psychiatr., 140 (1983) 243-244.

159 Larsen, J.K., Lindberg, M.A. and Skovgaard, B., Sleep deprivation as treatment for endogenous depression, Acta Psychiat. Scand., 54 (1976) 167.

160 Layman, J.M. and Milton, A.S., Some actions of $A^{1}$-tetrahydrocannabinol and cannabinoids at cholinergic functions, Brit. J. Pharmacol., 41 (1971) 379-380P.

161 Loh, Y.P., Proteolysis in neuropeptide processing and other neural functions, Ann. Rev. Neurosci., 7 (1984) 189-222.

162 Lomax, P., Foster, R.F. and Kirpatrick, W.E., Cholinergic and adrenergic interactions in the thermoregulatory centers of the rat, Brain Res., 15 (1969) 431-438.

163 Lomax, P. and Jenden, D.J., Hypothermia following systematic and intracerebral injection of oxotremorine in the art, Neuropharmacology, 5 (1966) 353-359.

164 Longo, V.G. and Silvestrini, B., Action of eserine and amphetamine on the electrical activity of the rabbit brain, $J$. 
Pharm. Exp. Ther., 120 (1957) 160-170.

165 Luqmanc, Y.A. et al., Depolarization-induced changes in Inuscarinic cholinergic receptors in synaptosomes, Nature (London), 271 (1979) 481-483.

166 Magherini, P.C., Pompeiano, O. and Thoden, U., The neurochemical basis of REM sleep: a cholinergic mechanism responsible for rhythmic activation of the vestibulooculomotor system, Rrain Res., 35 (1971) 565-569.

167 Magoun, H.W., Caudal and cephalic influences of the brain reticular formation. Physiol. Rev., 30 (1950) 459-474.

168 Makara, G.B. and Stark, E., The effects of cholinomimetic drugs and atropine on $\mathrm{ACTH}$ release, Neuroendocrinology, 21 (1976) 31-41.

169 McCarley, R.W. and Hobson, J.A., Single neuron activity in cat gigantocellular tegmental field: selectivity of discharge in desynchronized sleep, Science, 174 (1971) 1250-1252.

170 McCarley, R.W., REM sleep and depression - common neurobiological control mechanisms, Am. J. Psychiatr., 139 (1982) 565-570.

171 McVicar, K., Abuse of antiparkinson drug by psychiatric patients, Am. J. Psychiatr., 138 (1977) 809-811.

172 Meeter, E. and Wolthuis, O.L., The effects of cholinesterase inhibitors on the body temperature of the rat. Eur. $J$. Pharmacol., 4 (1960) 18-24.

173 Meyerson, L.R., Wennogle, L.P., Abel, M.S., Coupet, J., Lippa, A.S., Rauh, C.E. and Beer, B., Human brain receptor alterations in suicide victims, Pharmacol. Biochem. Behav., 17 (1982) 159-163.

174 Modestin, J.J., Schwartz, R.B. and Hunger, J., Zur Frage der Beeinflussung schizophrener Symptome durch Physostigmin, Pharmakopsychiatrie, 9 (1973) 300-304.

175 Morpurgo, C., Interaction of imipramine and desmethylimipramine with tremorine and oxotremorine in mice, Life Sci., 6 (1967) 721-731.

176 Myers, R.D. and Yaksh, T.L., Feeding and temperature responses in unrestrained rat after injections of cholinergic and aminergic substances into the cerebral ventricles, Physiol. Behav., 3 (1961) 917-928.

177 Nassrallah, H.A. and Coryell, W.A., Dexamethasone non-suppression predicts the antidepressant effects of sleep deprivation, Psychiatr. Res., 6(1982) 61-64.

178 Naumenko, E.B., Hypothalamic chemoreactive structures and the regulation of pituitary-adrenal function. Effects of local injections of norepinephrine, carbacol and serotonin into the brain of guinea pigs with intact brains and after mesencephalic transaction, Brain Res., 11 (1968) 1-10.

179 Naumenko, E.B., Role of adrenergic and cholinergic structures in the control of pituitary-adrenal system, Endocrinology, 8 (1967) 68-76.

180 Nomura, Y., Kajiyama, A. and Segawa, T., Possible influence of noradrenalin on $\beta$-adrenergic and muscarinic receptors in rat heart: effects of 6-hydroxydopamine, isoproterenol and desmethylimipramine. In T. Segawa et al. (Eds.), Moleculur Pharmacology and Neurotransmitter Receptors, Raven, New York, 1983, pp. 83-90.

181 Nomura, Y., Kajiyama, H. and Segawa, T., Alteration in sensitivity to isoproterenol and acetylcholine in the rat heart after repeated administrations of isoproterenol, $J$. Pharmacol. Exp. Ther., 220 (1982) 441-445.

182 Nordberg, A. and Wahlstrom, G., Changes in cholinergic function in the rat brain late in the abstinence after chronic barbital treatment, Drug Alcohol Depend., 7 (1981) $51-61$.

183 Nordberg, A. and Sundwall, A., The effect of sodium pentobarbital on the apparent turnover of acetylcholine in different brain regions, Acta Physiol. Scand., 99 (1977) $336-344$.

184 Nurnberger, J. Sitaram, N., Gerson, E.S. and Gillin, J.C., A twin study of cholinergic RFM induction, Biol. Psychiatr., 18 (1983) 1161-1165.

185 Olds, J., Self stimulation of the brain, Science, 14 (1958) 315-324

186 Olds, M. and Domino, E.F., Comparison of muscarinic and nicotinic cholinergic agonists on self-stimulation behavior, J. Pharmacol., 166 (1969) 189-204.

187 Olds, M.E., Alterations by centrally acting drugs of the suppression of self-stimulation behavior in the rat by tetrabenazine, physostigmine, chlorpromazine and pentobarbital, Psychopharmacology, 25 (1972) 299-314.

188 Olson, L. and Fuxe, K., Further mapping of central noradrenaline neuron systems: projections of the subcoeruleus' area, Brain Res., 4 (1972) 289-295.

189 Oppenheim, G., Ebstein, R.P. and Belmaker, R.H., Effect of lithium on the physostigmine-induced behavioral syndrome and plasma cyclic GMP, J. Psychiatr. Res., 15 (1979) $133-138$.

190 Osteid, A.M. and Aruguete, A., Central nervous system effects of hyosine in man, J. Pharmacol. Exp. Ther., 137 (1962) 13-139.

191 Overstreet, D.H. and Yamamura, H.I., Receptor alterations and drug tolerance, Life Sci., 25 (1979) 1865-1878.

192 Overstreet, D.H., Kozar, M.P. and Lynch, G.S., Reduced hypothermic effects of cholinomimetic agents following chronic anticholinesterase treatment, Neuropharmacology, 12 (1973) 1017-1032.

193 Palkovitz, M.. Neural pathways involved in ACTH regulation. Ann. NY Acad. Sci., 297 (1977) 455-476.

194 Parmeggiani, P.L., Telencephalo-diencephalic aspects of slecp mechanisms, Brain Res., 7 (1968) 350-359.

195 Paton, W.D.M., The action of morphine and related substances on contraction and on acetylcholine output ofcoaxially stimulated guinea pig ileium, Brit. J. Pharmacol., 125 (1957) 119-127.

196 Pattersen, U., Fyro, B. and Sedvall, G., A new scale for the longitudinal rating of manic states, Acta Psychiatr. Scand., 49 (1973) 248-256.

197 Pflug, B., The effect of sleep deprivation on depressed patients, Acta Psychiatr. Scand., 53 (1976) 148.

198 Pokony, A., Prediction of suicides in psychiatric patients: report of a prospective study, Arch. Gen. Psychiatr., 40 (1983) 249-254.

199 Pullen, G.P., Best, N.R. and Maguire, J., Anticholinergic drug abuse. A common problem?, Brit. Med. J., 289 (1984) 612-613.

200 Rabin, R.A., Wolfe, B.B., Dibner, M.D. et al., Effects of ethanol administration and withdrawal on neurotransmitter receptor systems in 157 mice, J. Pharmacol. Exp. Ther., 213 (1980) 491-496.

201 Rehavi, M., Ramot, O., Yavetz, B. et al., Amitriptyline: long-term treatment elevates $\alpha$-adrenergic and muscarinic receptor binding in mouse brain, Brain Res., 194 (1980) 443-453.

202 Richelson, E. and Dininetz-Romero, S., Blockade by psychotropic drugs of the muscarinic acetylcholine receptor in cultured nerve cells, Biol. Psychiatr. 12 (1977) 771-785. 
203 Risch, S.C., $\beta$-endorphin hypersecretion in depression: possible cholinergic mechanisms, Biol. Psychiatr., 17 (1982) 1071-1079.

204 Risch, S.C., Cohen, P.M., Janowsky, D.S. et al., Physostigmine induction of depressive symptomatology in normal human subjects, J. Psychiatr. Res., 4 (1981) 89-94.

205 Risch, S.C., Cohen, R.M., Janowsky, D.S., Kalin, N.H. and Murphy, D.L., Mood and behavioral effects of physostigmine on humans are accompanied by elevations in plasma beta-endorphin and cortisol, Science, 209 (1980) 1545-1546.

206 Risch, S.C., Janowsky, D.S., Parker, D. et al., Neuroendocrine abnormalities in affective disorders: Possible Cholinergic Mechanisms: In Post R.M. and Ballanger. J., The Neurobiology of Mood Disorders, Williams \& Wilkins, 1984.

207 Risch, S.C., Janowsky, D.S., Judd, L. and Huey, L., $\beta$-endorphin hypersecretion in depression possible cholinergic mechanisms. Collegium Internationale Neuro-Psychopharmacologium 13th C.I.W.P. Congress, Jerusalem, Israel, 1983, pp. 622.

208 Risch, S.C., Janowsky, D.S. and Gillin, J.C., Muscarinic supersensitivity of anterior pituitary ACTH and $\beta$-endorphin release in major depressive illness, Peptides, 4 (1983) 789-792.

209 Risch, S.C., Kalin, N.H. and Janowsky, D.S., Cholinergic challenges in affective illness: behavioral and neuroendocrine correlates, J. Clin. Psychopharmacol., 1 (1981) $186-192$.

210 Risch, S.C., Kalin, W.H., Janowsky, D.S., Cohen, R.M., Pickar, D. and Murphy, D.L., Co-release of ACTH and $\beta$ endorphin immunoreactivity in human subjects in response to central cholinergic stimulation, Science, 77 (1983) 222.

211 Rosenblatt, J.E., Janowsky, D.S., Davis, J.M. et al., The augmentation of physostigmine toxicity in the rat by $\Delta^{9}$-tetrahydrocannabinol, Res. Commun. Chem. Pathol. Pharmacol., 3 (1972) 479-481.

212 Rottanburg, D., Robins, A., Bon-Arie, G. et al., Cannabis-associated psychosis with hypomanic features, Lancet, 1 (1982) 1364-1366.

213 Rowntree, D.W., Neven, S. and Wilson, A., The effects of diisopropylfluorophosphate in schizophrenia and manic depressive psychosis, J. Neurol. Neurosurg. Psychiatr., 13 (1950) 47-62.

214 Roy, A. and Bhanji, S., Sleep deprivation treatment in depression: a review, Postgraduate Med., 52 (1976) 50-52.

215 Rubinstein, J.S., Abuse of antiparkinsonism drugs: feigning of extrapyramidyl symptoms to obtain trihexphenidyl, J. Am. Med. Assoc., 239 (1978) 2365-2366.

216 Rudorfer, M.V., Hwu, H.G. and Clayton, P.J., Dexamethasone suppression test in primary depression significance of family history and psychosis, Biol. Psychiatr., 17 (1982) 41-48.

217 Russell, R.W., Vasquez, B.J., Overstreet, D.H. and Dalglish, F.W., Effects of cholinolytic agents on behavior following development of tolerance to low cholinesterase activity, Psychopharmacology, 20 (1971) 32-41.

218 Russell, R.W., Vasquez, B.J., Overstreet, D.H. and Dalglish, F.W., Consummatory behavior during tolerance to and withdrawal from chronic depression of cholinesterase activity, Biochem. Behav., 7 (1971) 523-526.

219 Soli, N.E., Karlsen, R.L., Opsahl, M. and Fonnum, F., Correlation between acetylcholinesterase activity in guinea pig iris and pupillary functions: a biochemical and pupillographic study, J. Neurochem., 35 (1980) 723-728.

220 Sachar, E., ACTH and cortisol secretion in psychiatric disease, Ann. NY Acad. Sci., 297 (1977) 621-632.

221 Sageles, T., Erill, S. and Domino, E.F., Differential effects of scopolamine and chlorpromazine on REM and NREM sleep in normal male subjects, Clin. Pharmacol. Ther., 10 (1969) 522-529.

222 Schaumann, W., Inhibition by morphine of the release of acetylcholine from the intestine of the guinea pig, Brit. $J$. Pharmacol., 12 (1957) 115-118.

223 Schildkraut, J.J., The catecholamine hypothesis of affective disorders: a review of supporting evidence, $A m$. J. Psychiatr., 122 (1965) 509-522.

224 Schilgen, B. and Tölle, R., Partial sleep deprivation as therapy for depression, Arch. Gen. Psychiatr., 37 (1980) 267.

225 Schiller, G.D., Reduced binding of $\left[{ }^{3} \mathrm{H}\right]$ quinuclydinyl benzilate associated with low acetylcholinesterase activity, Life Sci., 24 (1979) 1159-1164.

226 Schuberth, J., Sparf, B. and Sondwall, A., A technique for the study of acetylcholine turnover in mouse brain in vivo, J. Neurochem., 16 (1969) 695-700.

227 Shopsin, B., Janowsky, D.S., Davis, J.M. et al., Rebound phenomena in manic patients following physostigmine, Neuropsychobiology, 1 (1975) 180-183.

228 Shur, E. and Checkly, S., Pupil studies in depressed patients: an investigation of the mechanism of outcome of desipramine, Brit. J. Psychiatr., 140 (1982) 181-184.

229 Shur, E.S., Checkley, E. and Delgado, I., Failure of mianserin to affect autonomic function in the pupils of depressed patients, Acta Psychiatr. Scand., 67 (1983) 50-55.

230 Sidman, M., Avoidance conditioning with brief shock and no exteroceptive warning signal, Science, 118 (1953) $157-158$.

231 Siman, R.G. and Klein, W.L., Cholinergic activity regulates muscarinic receptors in central nervous system cultures, Proc. Natl. Acad. Sci. U.S.A., 76 (1979) 4141-4145.

232 Sitaram, N., Mendelson, W.B., Wyatt, R.J. and Gillin, J.C., The time dependent induction of REM sleep and arousal by physostigmine infusion during normal human sleep, Brain Res., 122 (1977) 562-567.

233 Sitaram, N., Moore, A.M. and Gillin, J.C., Scopolamineinduced muscarinic supersensitivity in normal man: changes in sleep, Psychiatr. Res., 1 (1979) 9-16.

234 Sitaram, N., Nurnberger, J., Gershon, E. et al., Faster cholinergic REM sleep induction in euthymic patients with primary affective illness, Science, 208 (1980) 200-202.

235 Sitaram, N., Nurnberger, J.I., Gershon, E.S. and Gillin, J.C., Cholinergic regulation of mood and REM sleep: potential model and marker of vulnerability to affective disorder, Am. J. Psychiatr., 139 (1982) 571-576.

236 Sitaram, N., Wyatt, R.J., Dawson, S.J. and Gillin, C.J., REM sleep induction by physostigmine infusion during sleep, Science, 191 (1967) 1281-1283.

237 Sitaram, N. and Gillin, J.C., Development and use of pharmacological probes of the CNS in man: evidence of cholinergic abnormality in primary affective illness, Biol. Psychiatr., 15 (1980) 925-955.

238 Smith, J.M., Abuse of antiparkinson drugs: a review of the literature, J. Clin. Psychiatr., 41 (1980) 351-354.

239 Smith, T.L., Influence of chronic ethanol consumption on muscarinic cholinergic receptors and their linkage to phos- 
pholipid metabolism in mouse synaptosomes, Neuropharmacology, 22 (1983) 661-663.

240 Snider, R.M., McKinney, M., Forray, C. and Richelson, E., Neurotransmitter receptors mediate cyclic GMP formation by involvement of arachidonic acid and lipoxygenase, Proc. Natl. Acad. Sci. U.S.A., 81 (1984) 3905-3909.

241 Snyder, S.H. and Yamamura, H.L., Antidepressants and the muscarinic acetylcholine receptors, Arch. Gen. Psy. chiatr., 34 (1977) 236-239.

242 Sorscher, S.M. and Dilsaver, S.C., Antidepressant induced sexual dysfunction in males: due to cholinergic blockade?, J. Clin. Psychopharmacol, 5 (1985) 53-55.

243 Spitzer, R.L., Endicott, J. and Robbins, E. In Research Diagnostic Criteria, 2nd edn., State Department of Mental Hygiene, New York Psychiatric Institute, Biometrics Research, 1975.

244 Spitzer, R.L. and Endicott, J., Schedule for Affective Disorders and Schizophrenia, Biometrics Research Division, New York State Psychiatric Institute, New York, 1975.

245 Stanley, M., Cholinergic receptor binding in the frontal cortex of suicide victims, Am. J. Psychiatr., 141 (1984) $1432-1436$

246 Stark, P. and Boyd, E., Effects of cholinergic drugs on hypothalamic self-stimulation response rates of drugs, $A m$. J. Physiol., 205 (1963) 745-748.

247 Suzuki, T., Abe, K. and Hirose, T., Adrenocortical secretion in responsc to pilocarpine in dogs with hypothalamic lesions, Neuroendocrinology, 17 (1975) 75-82.

248 Szabadi, P., Gaszner, P. and Bradshaw, C.M., The peripheral anticholinergic activity of tricyclic antidepressants: comparison of amitriptyline and desipramine in human volunteers, Br. J. Psychiatr., 137 (1980) 433-439.

249 Szerb, J.C., The effect of tertiary and quaternary atropine on cortical acetylcholine output and on the electroencephalogram in cats, Can.J. Physiol. Pharmacol., 42 (1964) $303-314$

250 Tabakoff, B., Muroz-Marcus, M. and Fields, J.Z., Chronic ethanol feeding produces an increase in muscarinic cholinergic receptors in mouse brain, Life Sci., 25 (1979) $2173-2180$

251 Takeyasu, K., Uchida, S., Nogcchi, Y, et al, Changes in brain muscarinic acetylcholine receptors and behavioral responses to atropine and morphine in chronic atropine treated rats, Life Sci., 25 (1979) 585-592.

252 Taylor, J.E., El-Fakanay, E. and Richelson, E., Longterm regulation of muscarinic acetylcholine receptors on cultured nerve cells, Life Sci., 25 (1979) 2181-2187.

253 Tislow, R.F., Long-term therapy with anticholinergic drugs in psychiatric patients, Pharmacology, 29 (1970) $486 \mathrm{Ab}$.

254 Tislow, R.F., Short-term therapy with anticholinergic drugs in psychiatric patients, Fed. Proc., Fed. Am. Soc. Exp. Biol., 28 (1969) 2387.

255 Tollefson, G.D., Senogles, S.E., Frey, W.H. et al., A comparison of peripheral and central human muscarinic cholinergic receptor affinities for psychotropic drugs, Biol. Psychiatr., 17 (1982) 555-567.
256 Toyoda, J., Sasaki, K. and Kurihara, M., A polygraphic study on the effect of atropine on human nocturnal sleep, Folia Psychiatr. Neurol. Jpn., 20 (1966) 275-289.

257 Tsuchiya, K., Toru, M. and Kobayashi, T., Sleep deprivaton: changes of monoamine and acetylcholine, Life Sci., 8 (1969) 867-873.

258 Van Pragg, C.H.M., Depression, Lancet, 2 (1982) $1259-1263$

259 Vernikos-Danellis, J., Kellar, K.J., Kent, D., Gonzales, C., Berger, P.A and Barchas, J.D., Serotonin involvement in pituitary-adrenal function, Amn. NY Acad. Sci. 297 (1977) 518-526.

260 Vogel, G.W., Thurmond, A., Gibbons, P. et al., The effect of REM deprivation on depression, Psychosomatics, 14 (1973) 104-107

261 Vogel, G.W., Vogel, F., McAbee, R.S. and Thurmond, A.J., Improvement of depression by REM sleep deprivation, Arch. Gen. Psychiatr., 37 (1980) 247-253.

262 Wahlstrom, G. and Ekwall, T., Tolerance to hexobarbital and supersensitivity to pilocarpine after chronic barbital treatment, Eur. J. Pharmacol., 32 (1976) 123-129.

263 Wahlstrom, $G$. and Nordberg, A., Sensitivity to an active synaptosomal uptake of choline in the abstinence after chronic barbital treatments, Acta Physiol. Scand., Suppl. 473 (1979) 65-203.

264 Wahlstrom, G., Estimation of brain sensitivity to the convulsive effects of choline and changes induced by chronic barbital treatments in the rat, Eur. $J$. Pharmacol., 51 (1978) 219-227.

265 Webb, W.B. and Campbell, S.S., Sleep characteristic relationship of identical and fraternal twins, Arch. Gen. Psychiatr, 40 (1983) 1093.

266 Weiss, B.L., Foster, F.G. and Kupfer, D.J., Cholinergic involvement in neuropsychiatric syndromes. In A.M. Goldberg and I. Hanin (Eds.), Biology of Cholinergic Function, Raven, New York, 1976, pp. 612-617.

267 White, R.P., Rinaldi, R. and Himwich, H.E., Central and peripheral nervous effects of atropine sulfate and mepiperphenidol bromide (darstine) on human subjects, $J$. Appl. Physiol, 8 (1956) 635-642.

268 Wilson, W.P. and Hughes, J.L., Observations on the effects of JB-329 (Ditran) on the electroencephalogram of man, J. Neuropsychiatr., 3 (1962) 310-315.

269 Wise, B.C., Shojim and Kyo, J.F., Decrease or increase in cardiac muscarinic cholinergic receptor number in rats treated with methacholinc or atropine, Biochem. Biophys. Res. Commun., 92 (1980) 1132-1142.

270 Yamada, S., Iogai, M., Okudaira, H. and Hayashi, E., Regional adaptation of muscarinic receptors and choline uptake in brain following repeated administration of diisopropylfluorophosphonate and atropine, Brain Res, 268 (1983) 315-320.

271 Yoshimura, H., Fujiwara, M. and Ueki, S., Biochemical correlates in mouse-killing behavior of the rat: brain acetylcholine and acetylcholinesterase after administration of $4^{9}$-tetrahydrocannabinol, Brain Res., 81 (1974) 567-570. 